Revue des patrimoines

27 | 2015

Le cheval et ses patrimoines (2e partie)

\title{
Les chevaux de la tapisserie de Bayeux
}

\section{Pierre Bouet}

\section{OpenEdition}

\section{Journals}

Édition électronique

URL : http://journals.openedition.org/insitu/11967

DOI : 10.4000/insitu. 11967

ISSN : 1630-7305

\section{Éditeur}

Ministère de la culture

\section{Référence électronique}

Pierre Bouet, «Les chevaux de la tapisserie de Bayeux », In Situ [En ligne], 27 | 2015, mis en ligne le 02 novembre 2015, consulté le 01 mai 2019. URL : http://journals.openedition.org/insitu/11967 ; DOI 10.4000/insitu. 11967

Ce document a été généré automatiquement le 1 mai 2019.

\section{(a) $\odot \Theta \Theta$}

In Situ Revues des patrimoines est mis à disposition selon les termes de la licence Creative Commons Attribution - Pas d'Utilisation Commerciale - Pas de Modification 4.0 International. 


\title{
Les chevaux de la tapisserie de Bayeux
}

\author{
Pierre Bouet
}

Les dessinateurs de la tapisserie de Bayeux avaient une excellente connaissance des chevaux et de l'art équestre, comme le montrent les 182 représentations de ces animaux, parmi lesquels on compte toutefois deux mulets et deux ânes. La tapisserie de Bayeux offre un témoignage exceptionnel sur une société où le cheval tenait une place essentielle ${ }^{1}$. C'est vraisemblablement Odon, évêque de Bayeux et demi-frère du Conquérant, qui a inspiré cette œuvre magistrale, pour démontrer la légitimité de la conquête de l'Angleterre par les Normands. Il voulait également défendre la politique de réconciliation entre vainqueurs et vaincus, que le nouveau roi normand imposa au lendemain de son couronnement. C'est pour cette raison que le personnage de Harold est constamment représenté de manière favorable: on insiste sur sa piété (fig. 1), son héroïsme (fig. 2) et sa légitimité (fig. 3). Cette politique favorable aux Anglais fut de courte durée et mise en échec dès les années 1070, lorsque des révoltes éclatèrent aussi bien dans l'Ouest du royaume que dans le Nord. À partir de cette date, il ne fut plus question de réconciliation et ce fut l'ordre normand qui s'appliqua dans toute sa rigueur. La propagande normande fit alors de Harold un parjure et un traitre qui s'était injustement approprié la couronne d'Angleterre. Pour ces raisons, nous avons émis l'hypothèse que la broderie de Bayeux n'avait pu être conçue et réalisée qu'au lendemain de la bataille d'Hastings, nécessairement avant 1070, date de ce changement brutal de politique $^{2}$. 
Figure 1

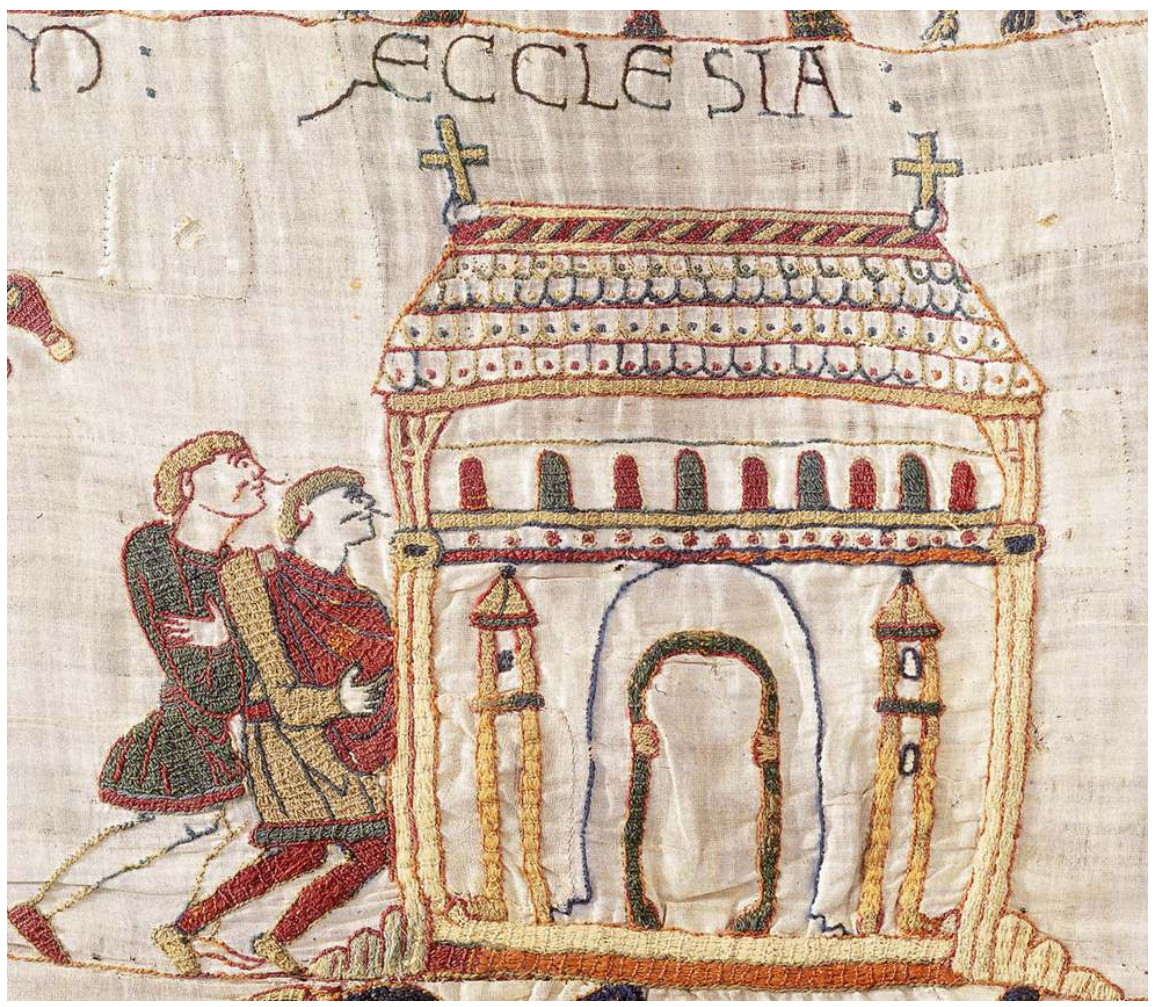

Scène 3 : Harold en prière dans l'église de Bosham.

(c) Musées de la ville de Bayeux. 
Figure 2

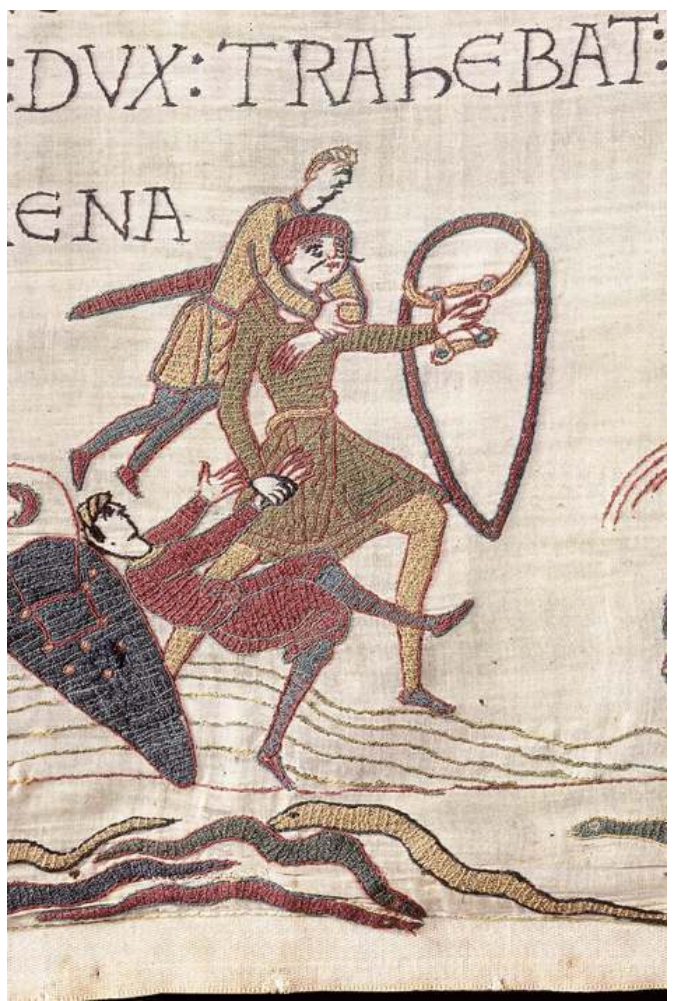

Scène 17 : Harold sauve deux hommes des sables mouvants dans la baie du Mont Saint-Michel. (c) Musées de la ville de Bayeux.

Figure 3

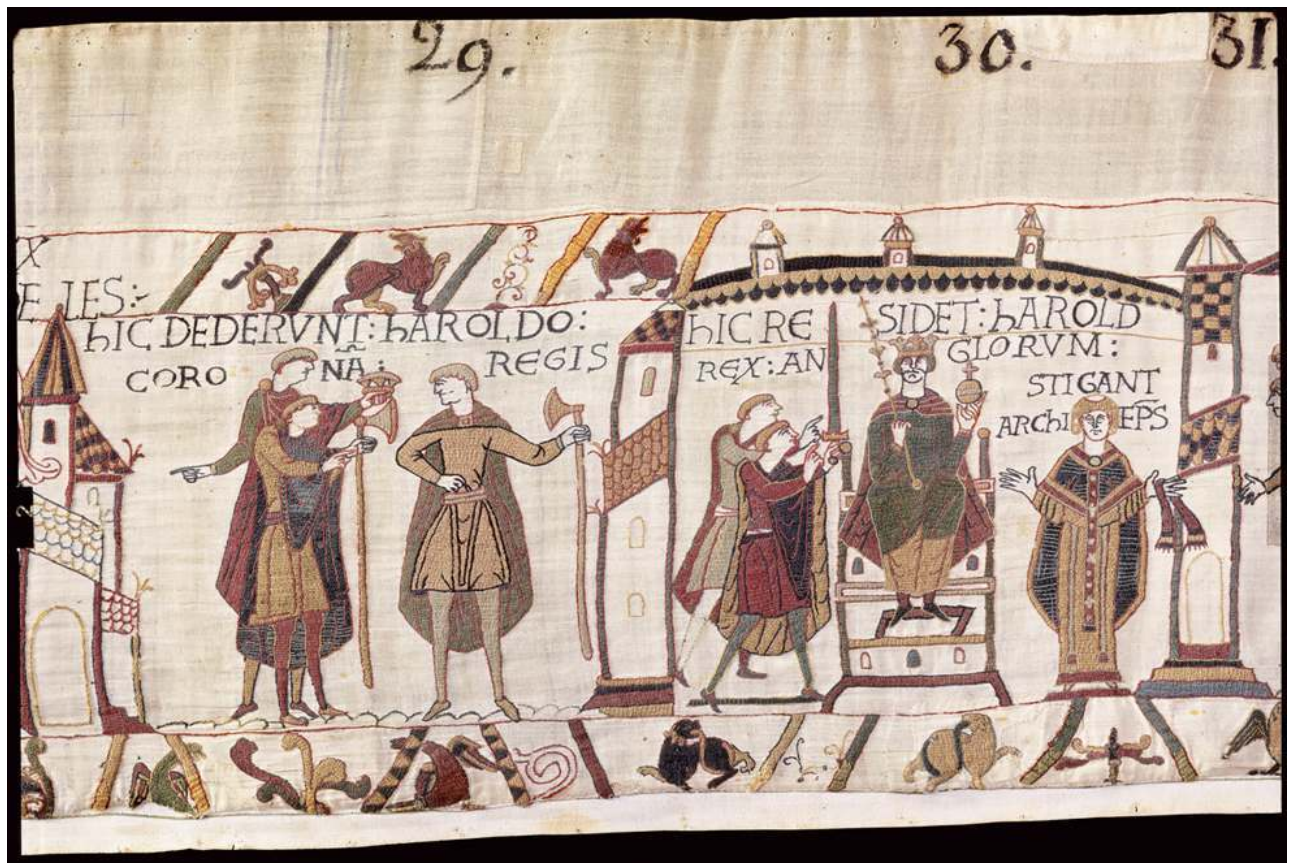

Scène 29 : Deux aristocrates remettent à Harold les insignes du pouvoir royal : l'un d'eux désigne la scène précédente où Édouard, sur son lit de mort, a transmis son trône à Harold.

(c) Musées de la ville de Bayeux. 
On s'est souvent servi de cette broderie, représentant les différentes phases de la bataille, pour opposer les fantassins anglais, armés d'épées ou de haches, aux Normands qui combattaient à cheval avec la lance comme arme privilégiée. On sait que sur les 8000 hommes présents sur le champ de bataille de Hastings et commandés par le duc de Normandie, il y avait environ 3000 chevaliers: le reste de l'armée était composée d'archers, bien visibles sur la broderie, et de fantassins, quasiment absents des scènes de combat. Pour des raisons esthétiques évidentes, les dessinateurs de la tapisserie de Bayeux ont choisi de montrer l'opposition entre Anglais et envahisseurs continentaux par le contraste fantassins/chevaliers (fig. 4). Il était difficile, en effet, de mettre en scène des affrontements de fantassins anglais et de fantassins continentaux puisque rien ne les distinguait dans la tenue et l'armement. Même si les combattants à pied engagés par le duc Guillaume ont joué un rôle important dans la bataille, ils n'ont guère eu le droit de figurer sur la broderie. C'est ce qui explique le grand nombre de représentations de chevaux sur la tapisserie de Bayeux.

Figure 4

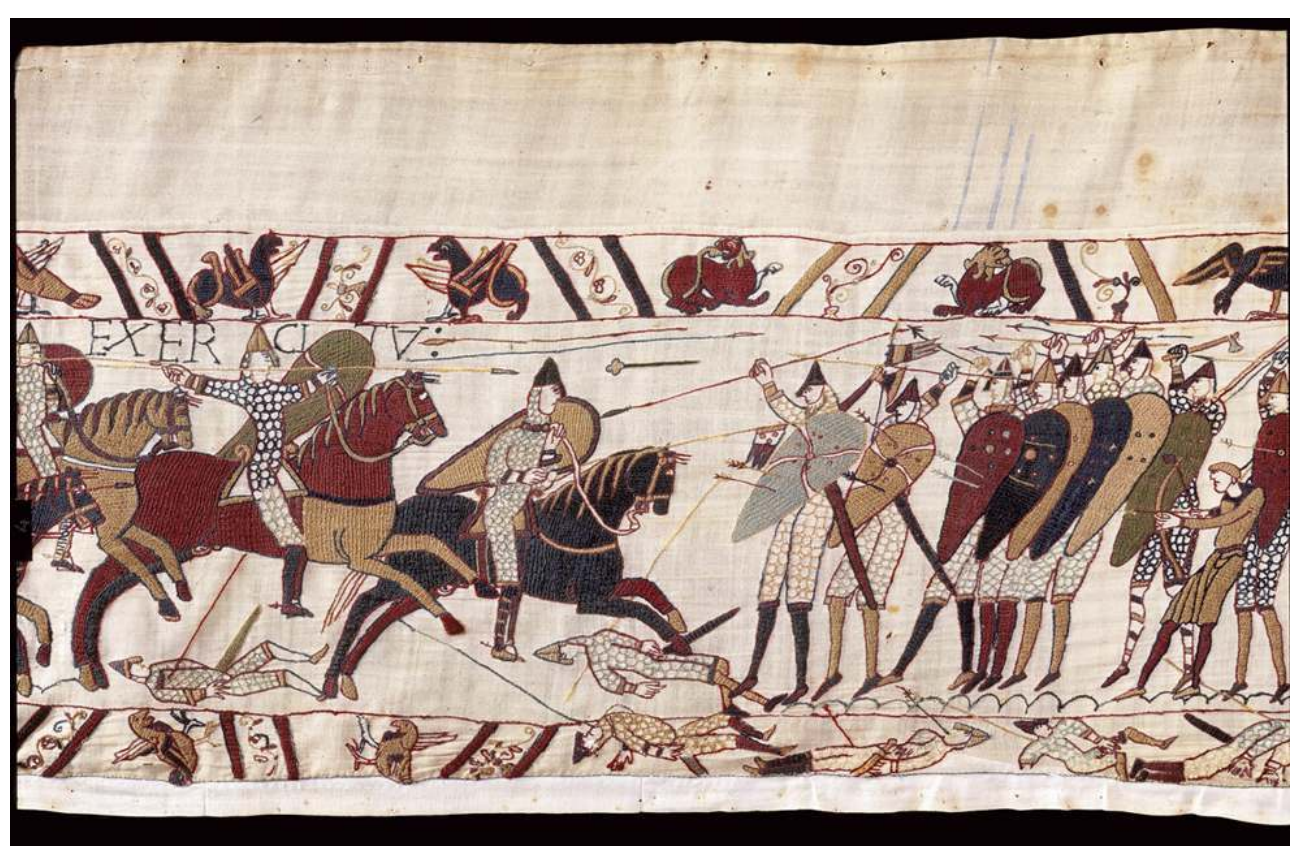

Scène 51/5:2 : Le face-à-face des fantassins anglais et des chevaliers normands.

(C) Musées de la ville de Bayeux.

\section{Intérêt documentaire}

L'étude documentaire sur les chevaux s'en trouve facilitée. Rien ne distingue les chevaux anglais des chevaux normands, même si les traditions et les coutumes étaient bien différentes en ce domaine de part et d'autre de la Manche. En Angleterre, le cheval était uniquement utilisé comme moyen de transport. Un Normand qui avait suivi Édouard le Confesseur en Angleterre en 1042 avait formé une cavalerie à la normande pour combattre les Gallois. Après avoir subi plusieurs échecs dramatiques, Édouard et Harold lui interdirent l'utilisation du cheval à la guerre. Dans les chartes anglo-saxonnes, les chevaux qui faisaient l'objet d'achat ou d'échanges étaient toujours évalués, à peu de 
chose près, au même prix, alors qu'en Normandie, la valeur de ces animaux variait selon une échelle de 1 à 40. Les sources écrites nous apprennent, en outre, que, dans le duché de Normandie, on accordait un grand intérêt à l'élevage des chevaux. Dès l'époque carolingienne, on avait créé de nombreux haras, où l'on pratiquait déjà l'amélioration de la race. Les ducs normands, en héritant de tous ces centres, ne cessèrent à leur tour de développer l'élevage des chevaux et de pratiquer des croisements. Ils le firent à partir notamment de chevaux espagnols, qui eux-mêmes avaient du sang des Barbes et des Barbes arabes du Maghreb.

4 Les sources écrites confirment ces liens entre la Normandie et la péninsule Ibérique. Dès le début du XI $\mathrm{I}^{\mathrm{e}}$ siècle, plusieurs seigneurs comme les Crespin ou les Tosny se rendirent en Espagne pour participer à la Reconquête chrétienne. Ils s'y révélèrent d'ailleurs particulièrement efficaces et barbares, durant plus d'un siècle. Selon Guillaume de Poitiers, le biographe du Conquérant, qui écrivit vers 1075 une Vie de Guillaume, duc des Normands et roi des Anglais, le Bâtard reçut, au lendemain de sa victoire au Val-ès-Dunes en 1047, de nombreux présents des autres princes de Francia. Les plus précieux de ces dons étaient des chevaux de grand prix: «De Gascogne et d'Auvergne, on lui envoya des chevaux, connus par leur nom propre. C'est par de tels présents que les rois espagnols sollicitèrent son alliance ${ }^{3} »$. À Hastings, Guillaume se présenta monté sur un cheval espagnol qu'un de ses barons, Gautier Giffard, en revenant de son pèlerinage à SaintJacques de Compostelle, lui avait ramené d'Espagne.

5 Tous les seigneurs normands avaient nécessairement leurs haras, puisqu'ils devaient présenter un ou plusieurs chevaliers avec l'équipement complet au service d'ost du duc. Les abbayes qui avaient des obligations temporelles possédaient également leurs centres d'élevage ${ }^{4}$.

6 Les chevaux normands de la tapisserie de Bayeux sont de petite taille: cela n'est nullement dû à un manque de proportion ou d'échelle, que l'on constate souvent entre les représentations des hommes et celles des monuments. Ces chevaux ne mesurent guère plus de 1,40 mètre au garrot. Ils pèsent environ 400, voire 500 kilos alors que nos Percherons d'aujourd'hui pèsent plus de 800 kilos. Richard d'Aversa, en raison de sa grande taille, avait les pieds qui parfois touchaient le sol. Ce cheval normand est un animal puissant, rapide et d'une extraordinaire docilité : il a été dressé et entraîné pour le combat. À côté de ce cheval que l'on appelle souvent « destrier » ou " chargeur », il existe aussi des chevaux de marche ou de parade, comme les palefrois, des animaux de trait, qui ont tendance à remplacer peu à peu les couples de bœufs dans les travaux agricoles, et des chevaux de somme, les « roncins».

7 L'équipement des chevaux est représenté avec une grande précision, ce que confirme toujours l'archéologie. La selle est constituée d'une ossature en bois de hêtre recouverte d'une peau en cuir. On distingue sur toutes les représentations le pommeau proéminent à l'avant et le troussequin à l'arrière. Sur les côtés, la selle est dotée de faux quartiers qui protègent les flancs des animaux. Il est rare de pouvoir apercevoir le tapis qui était disposé sous la selle, solidement fixée par deux sangles (fig. 5) : l'une qui passe sous le ventre du cheval (la sous-ventrière), l'autre (la bricole) qui entoure son poitrail, pour empêcher que la selle ne recule. On ne voit jamais de croupière. 
Figure 5

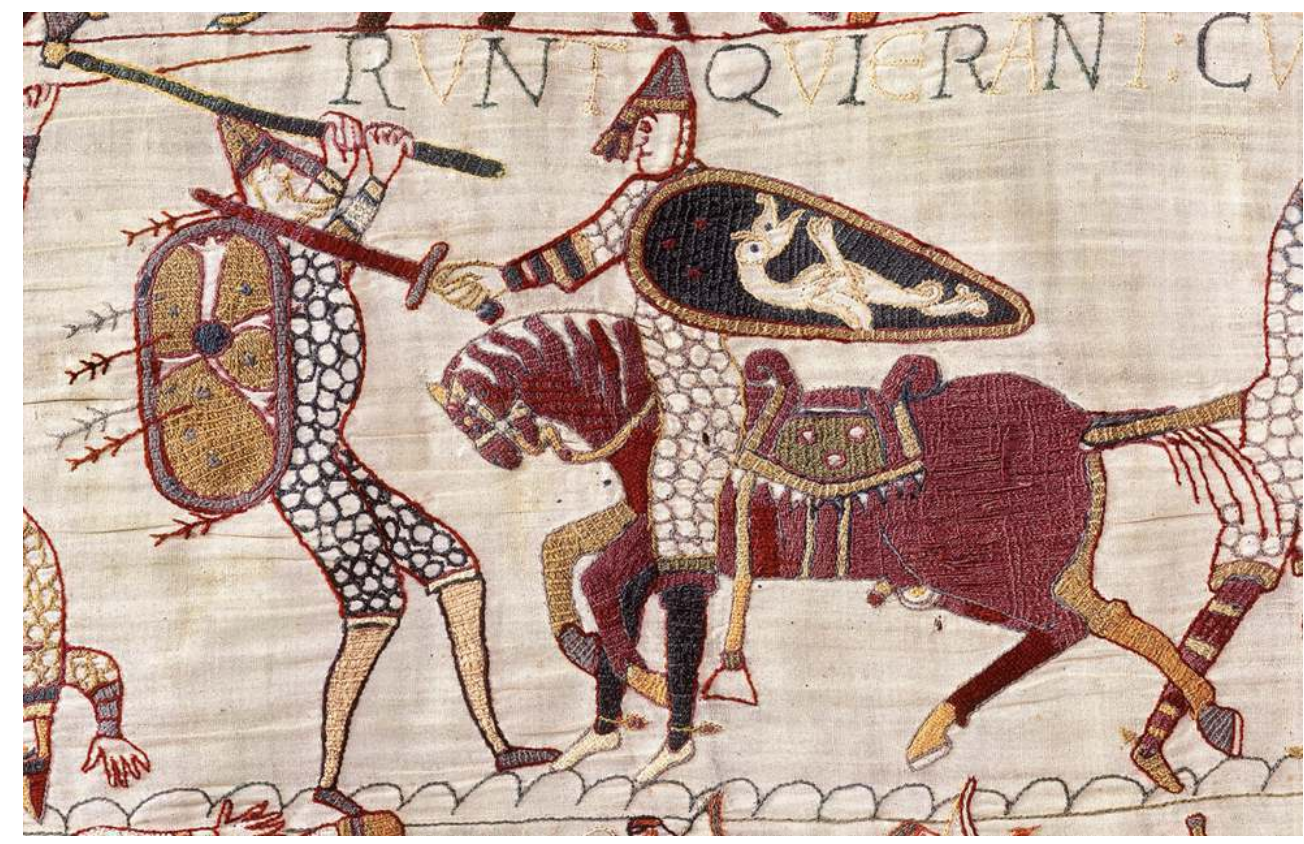

Scène 56 : On distingue nettement le tapis disposé sous la selle.

(c) Musées de la ville de Bayeux.

8 Une courroie de cuir, l'étrivière, est fixée au devant de la selle, par-dessus le quartier qui recouvre le faux-quartier et l'attache de la sangle. Cette étrivière descend très bas, de sorte que le cavalier, assis sur son cheval, semble debout sur ses étriers (fig. 6). Tous les chevaliers ont les jambes bien droites ou légèrement fléchies : ces trois points d'appui (selle et étriers) donnent une excellente assise au chevalier pour tenir, dans la main gauche, les rênes et le bouclier et, dans la main droite, la lance ou l'épée. Le combattant peut se retourner, lancer des javelots ou perforer l'adversaire avec sa lance fermement tenue sous le bras. 
Figure 6

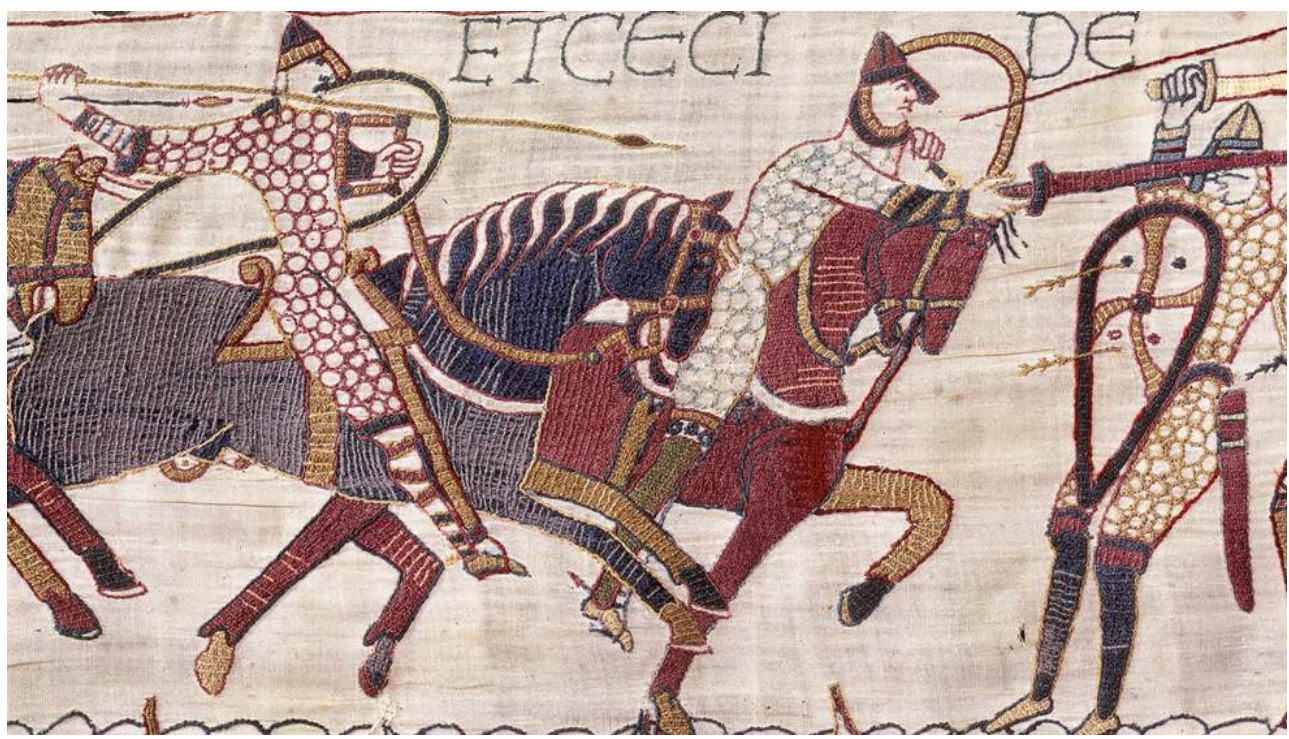

Scène 56 : Le chevalier normand qui abat un Anglais est assis sur son cheval tout en étant debout sur ses étriers

(c) Musées de la ville de Bayeux.

9 L'autre partie du harnachement, qui est bien visible sur les représentations des chevaux, est la bride qui comprend la têtière, le frontal, la sous-gorge, la muserolle, les montants auxquels est attaché le mors qui passe dans la bouche du cheval. Le mors a presque toujours la forme d'un $\mathrm{S}$ ou d'un 5 (fig. 7). Tous ces éléments du filet sont parfaitement dessinés. Les rênes sont fixées à l'anneau du mors : ce sont soit des rênes fermées, soit des rênes ouvertes, qui sont alors attachées par une olive. Au moment de leur transport dans les navires, les chevaux ne portent pas le filet, mais seulement le licol.

Figure 7

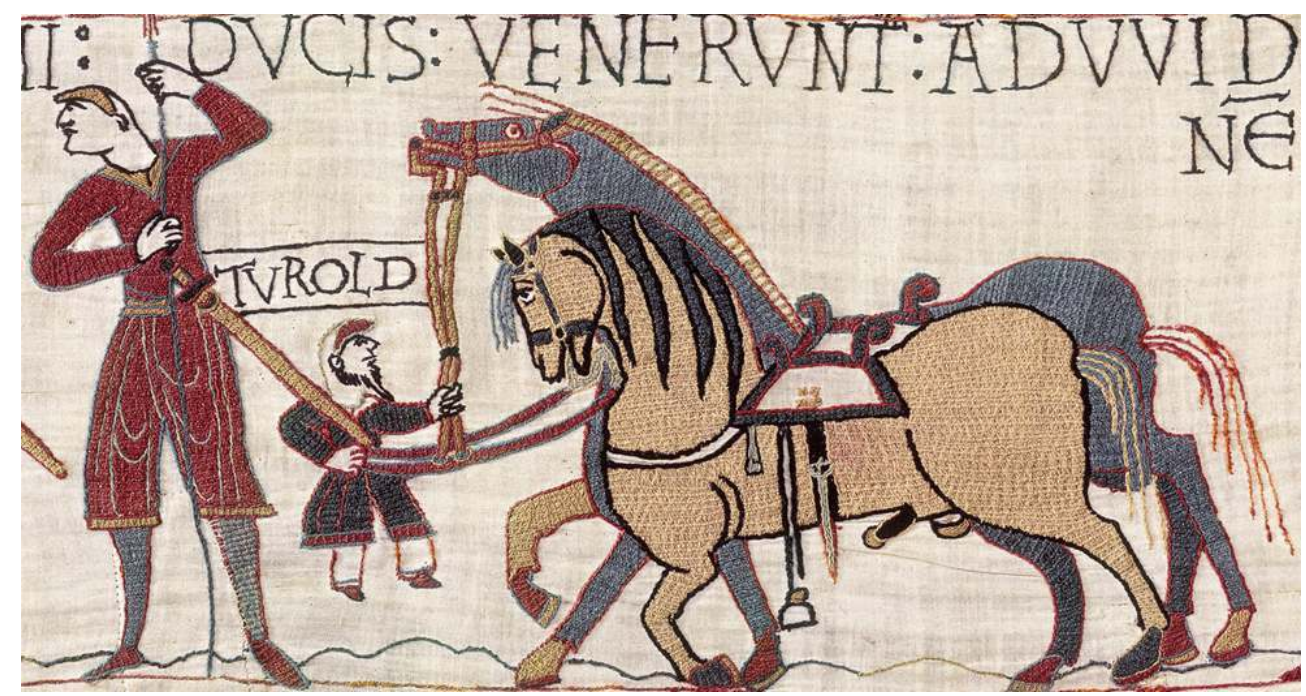

Scène 10 : Les pièces du harnachement des chevaux sont bien visibles sur la plupart des représentations.

(C) Musées de la ville de Bayeux. 
Certains chevaux ont droit à des décorations que l'on remarque soit sur la selle, soit sur la bricole (fig. 8). Le souci d'exactitude se manifeste encore dans la représentation des fers que portaient les chevaux. Comme l'ont confirmé les découvertes archéologiques, les chevaux étaient ferrés sous les sabots, ce qui a dû nécessiter dans l'expédition en Angleterre la présence de forgerons et de maréchaux-ferrants, à côté des bourreliers et des palefreniers. Sur certaines représentations, le sabot du cheval semble recouvert d'une sandale. Dans l'Antiquité, l'hipposandale était d'usage courant : elle était constituée d'une pièce métallique remontant légèrement sur le sabot et tenue par des lacets de cuirs. Mais l'usage de ces hipposandales a été abandonné assez tôt, au profit des fers qui se sont imposés définitivement au début du IX $\mathrm{I}^{\mathrm{e}}$ siècle.

Figure 8

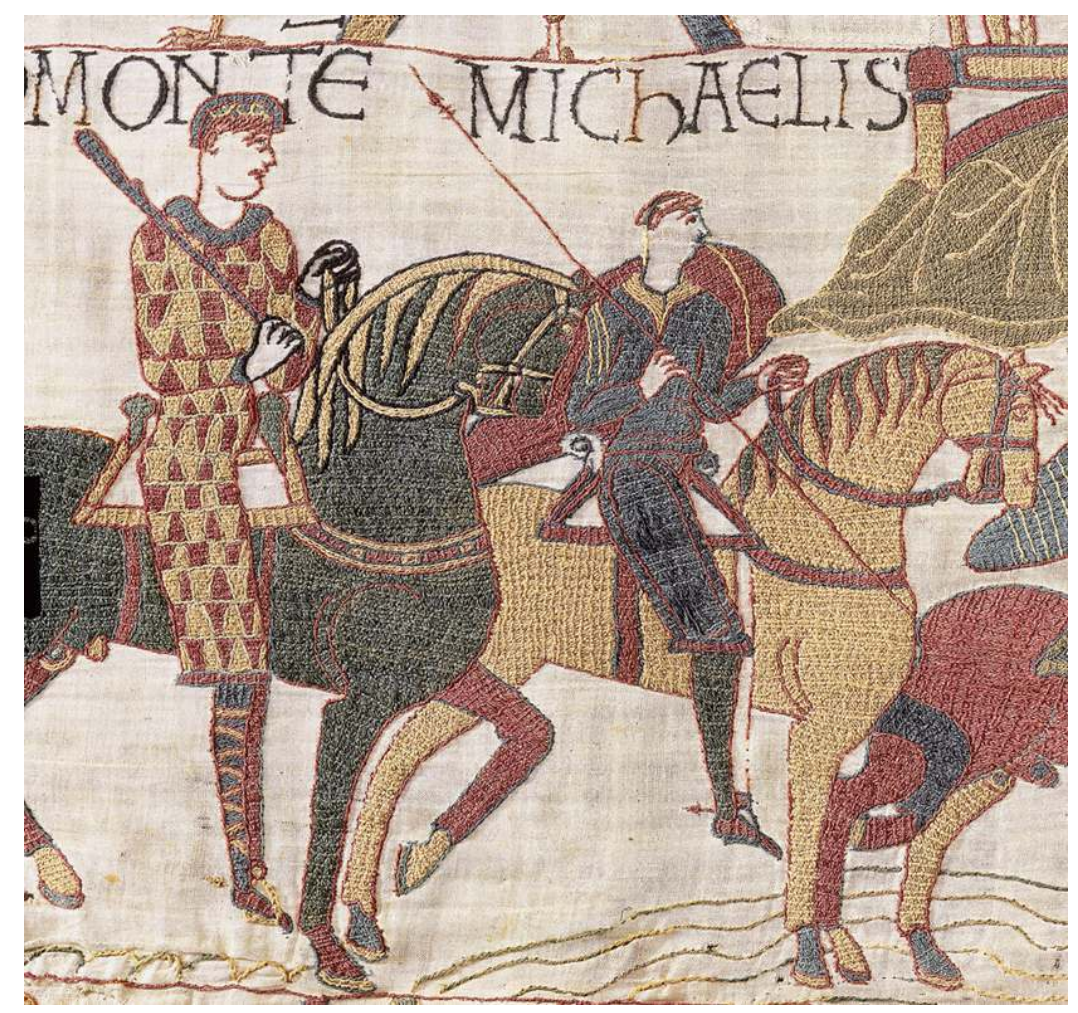

Scène 16 : Cheval de Guillaume avec la bricole décorée.

(c) Musées de la ville de Bayeux.

Les chevaux de la tapisserie de Bayeux présentent une autre particularité : on n'hésite pas à dessiner leur parties sexuelles, c'est-à-dire testicules et fourreau, quelquefois en érection. La cavalerie normande était, en effet, constituée pour une part importante de chevaux entiers, et non d'étalons qui auraient été incontrôlables. Il y eut probablement aussi des hongres, c'est-à-dire des chevaux castrés. 


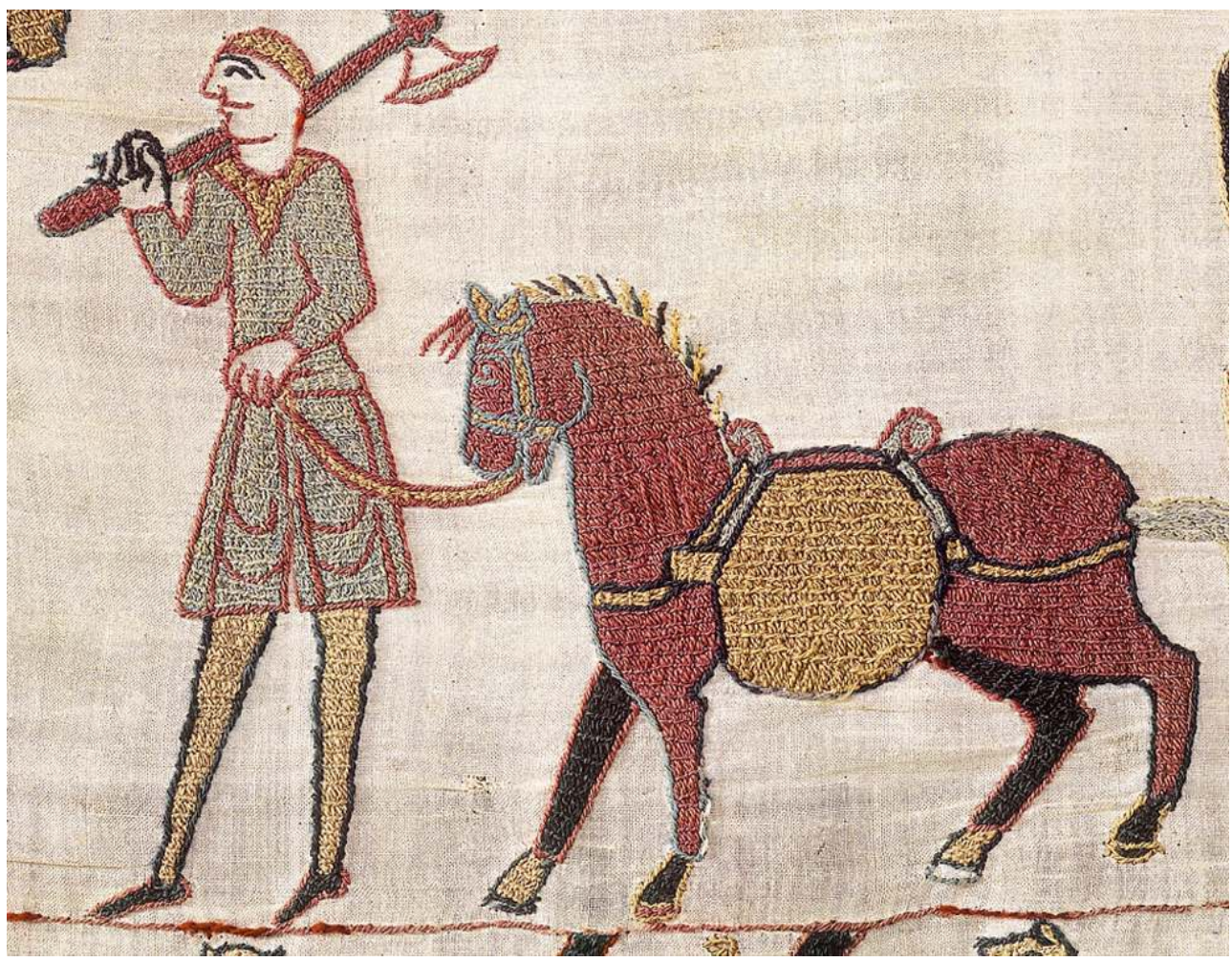

Scène 41 : Le cheval de bât.

(c) Musées de la ville de Bayeux.

Quelques représentations de chevaux de trait ou de somme méritent notre attention. Le cheval de bât de la scène 45 , avec sa crinière en brosse, est plus petit que les autres chevaux (fig. 9) : l'était-il réellement ou y a-t-il une volonté de représenter ce sommier comme un animal moins prestigieux ? La charge qui pend sur les flancs est tenue à la fois par une bricole, par une sangle sous le ventre que l'on ne voit pas et par une avaloire qui passe sur la croupe. Dans la scène 10 (fig. 10), on aperçoit un cheval qui tire une herse (dont c'est la première figuration). Grâce au collier d'épaule, que l'on distingue clairement, le cheval a acquis une puissance de traction considérable: de ce fait, on en fait un animal de trait dans les travaux agricoles à la place des bœufs, qui resteront cependant en service durant de nombreux siècles encore. Juste avant cette scène de hersage, c'est un mulet avec collier d'épaule qui tire une charrue à roue, dotée d'un soc à versoir (fig. 11). La tapisserie de Bayeux présente ici un témoignage exceptionnel de ce que l'on pourrait appeler la "révolution du cheval», dont la Normandie a été une terre d'élection. On ne peut pas ne pas noter la simultanéité du développement du cheval de guerre et du cheval de trait en Normandie en ce $\mathrm{xI}^{\mathrm{e}}$ siècle. 


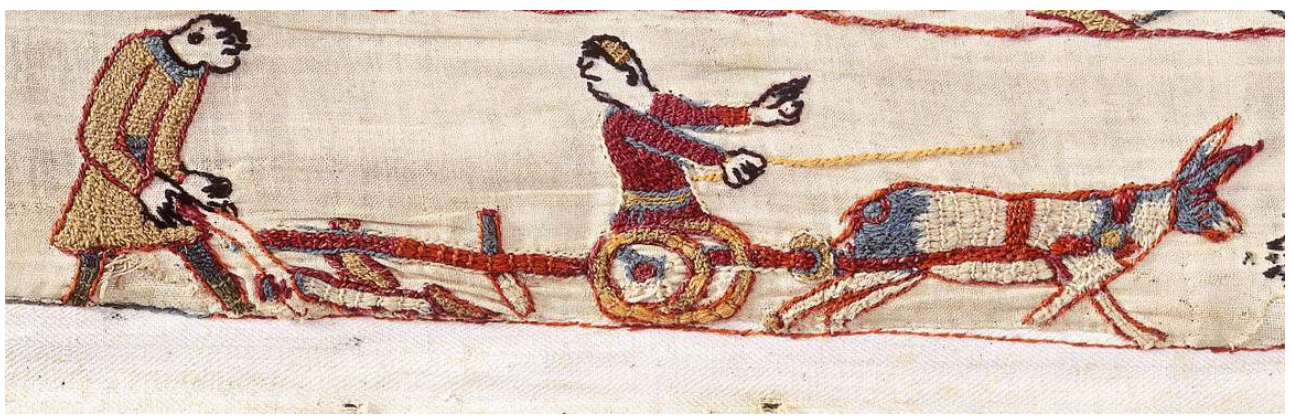

Scène 10 : Un mulet tire une charrue.

(c) Musées de la ville de Bayeux.

Figure 11

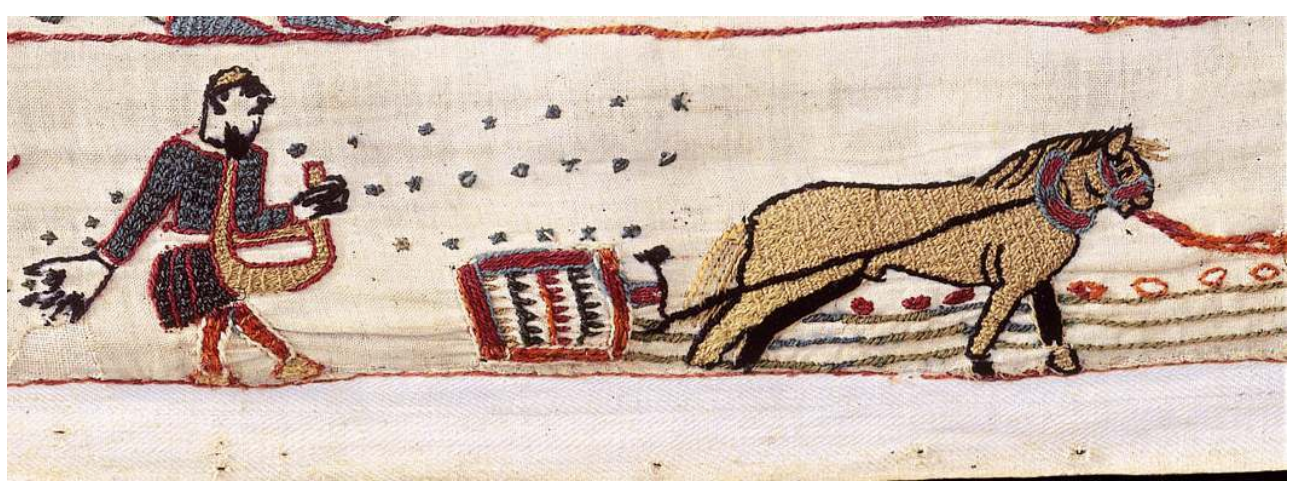

Scène 10 : Un cheval tire une herse.

(c) Musées de la ville de Bayeux.

La tapisserie de Bayeux n'apporte pas de réponses à toutes nos interrogations. Elle ne fait aucune allusion aux opérations d'approvisionnement des 5000 chevaux parqués dans les environs de la baie de Dives-sur-mer, puis dans l'estuaire de la Somme, pendant dix semaines, du 15 juillet au 28 septembre 1066. Or, nous pouvons calculer que ces animaux ont eu besoin d'un apport de 1500 tonnes d'avoine ou d'orge, de 1200 tonnes de foin et de 400 tonnes de paille. Les forgerons et maréchaux-ferrants ont dû travailler quelque 20 tonnes de fer pour les clous et les fers des chevaux. Elle ne fait aucune allusion non plus à la délicate manœuvre de l'embarquement de ces 5000 chevaux en quelque cinq ou six heures. Les sources écrites évoquent, sans fournir de précisions, la réussite de cette opération en quelques heures. Les navires vikings, sans quille, exigeaient une parfaite stabilité pour embarquer des chevaux. Une fois les bateaux immobilisés au sol par des cales à marée basse, les chevaux étaient conduits dans les navires sur un plan incliné par des palefreniers qui veillèrent sur eux durant les seize heures d'immobilité. C'est la marée montante qui souleva alors les navires sans heurt et le reflux de la Somme les entraîna vers la haute mer ${ }^{5}$.

\section{Un intérêt esthétique}

Ce souci documentaire n'est nullement incompatible avec la volonté de montrer le cheval dans toute sa splendeur. C'est principalement par les chevaux que les dessinateurs de la 
tapisserie de Bayeux ont réussi à donner vie et mouvement aux différentes scènes du récit. Ils ont d'abord voulu privilégier la variété des représentations: variété des couleurs, des crinières, des allures et des postures. Prisonniers des couleurs des laines, ils ont joué sur cette gamme de couleurs pour donner l'impression de groupes compacts, où les différents chevaux sont aisément reconnaissables. Le comptage des chevaux selon leur couleur est évidemment purement anecdotique et n'a guère de signification : les chevaux de couleur jaune/beige sont majoritaires (au nombre de 57) et les chevaux vert foncé ou vert clair les moins nombreux (26), tandis que les rouges et les bleu noir occupent une place importante avec respectivement 45 et 38 individus. Les anomalies sont rares, et peut-être dues à des restaurateurs peu attentifs : à la scène 51 , le cheval rouge se voit attribuer la partie inférieure avant en laine jaune. Il est quelque peu audacieux d'oser établir un parallélisme entre les couleurs et les robes des chevaux. Comme les crinières sont toujours d'une couleur différente de la robe, on pourrait supposer que les dessinateurs voulaient mettre en scène des chevaux bais, isabelle ou souris.

Les crinières présentent une grande diversité : crinières flottantes et naturelles (voir fig. 5), crinières bien égalisées (voir fig. 6), crinières hérissées (voir fig. 9), sans doute coupées à moins de $8 \mathrm{~cm}$, crinières en brosse ou crinières nattées (voir fig. 7). Le toupet est toujours présent sur la tête du cheval entre les deux oreilles; cette tête est soit légèrement inclinée, soit bien tendue vers l'avant, soit dans une position normale. La queue est relâchée quand l'animal est immobile ou à l'horizontale lorsqu'il est au galop.

Figure 12

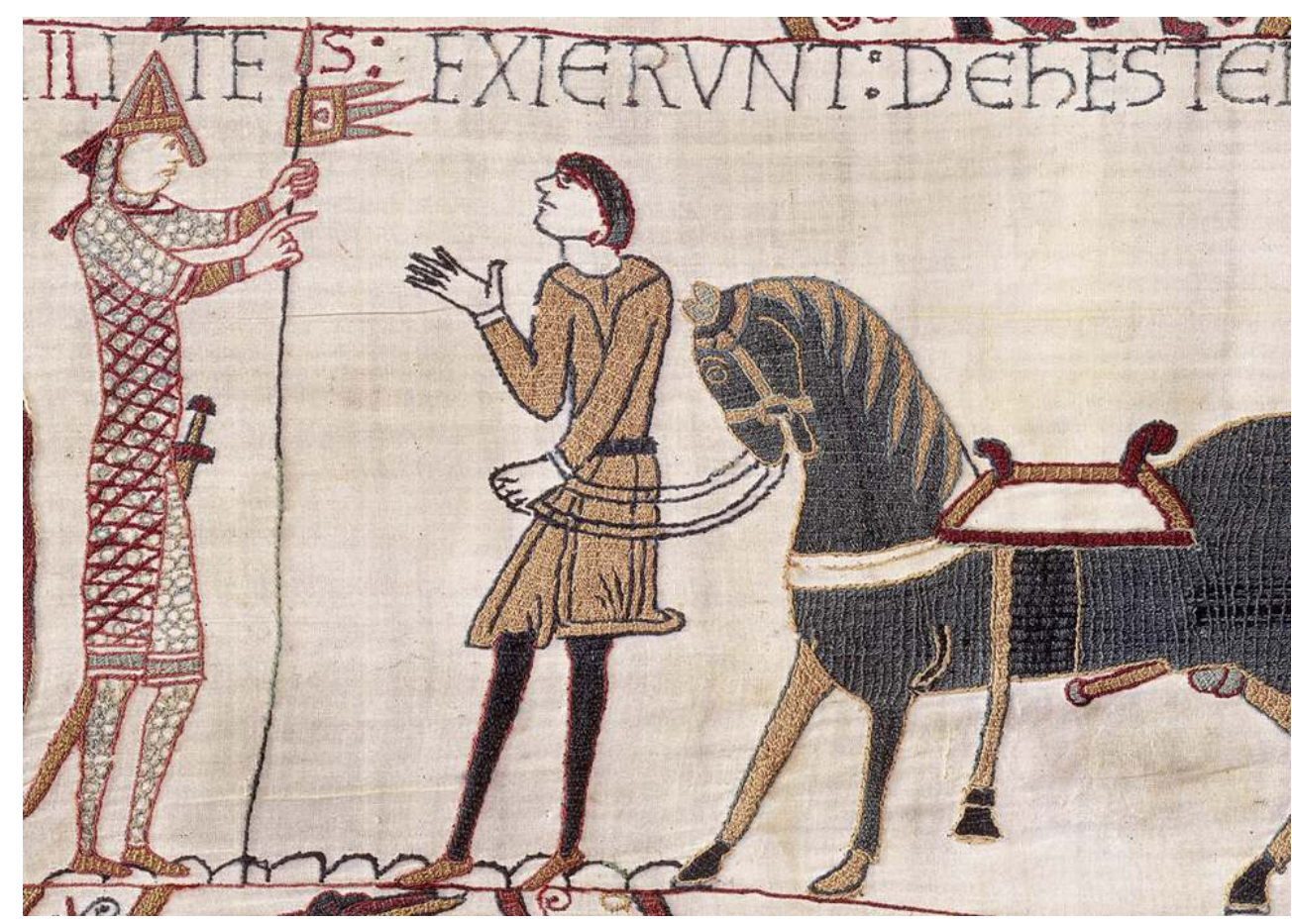

Scène 47/48 : Le destrier immobile de Guillaume.

(c) Musées de la ville de Bayeux.

Les dessinateurs ont eu le souci de représenter les différentes allures des chevaux : l'arrêt, le pas, le trot et le galop. On le voit immobile, les quatre sabots bien plantés au sol, quand le duc Guillaume se prépare à monter son destrier (fig. 12) : selon les sources écrites, ce serait un cheval espagnol ramené par Gautier Giffard ${ }^{6}$. On sait par son biographe, 
Guillaume de Poitiers, qu'il eut au cours de la bataille trois chevaux tués sous lui ${ }^{7}$. Il marche au pas lorsqu'un de ses membres antérieurs est levé (scène 8) : seul l'avant-bras du membre est redressé, formant un angle droit avec la partie inférieure (canon, boulet, sabot); parfois il semble que le postérieur en diagonale se relève (fig. 13).

Figure 13

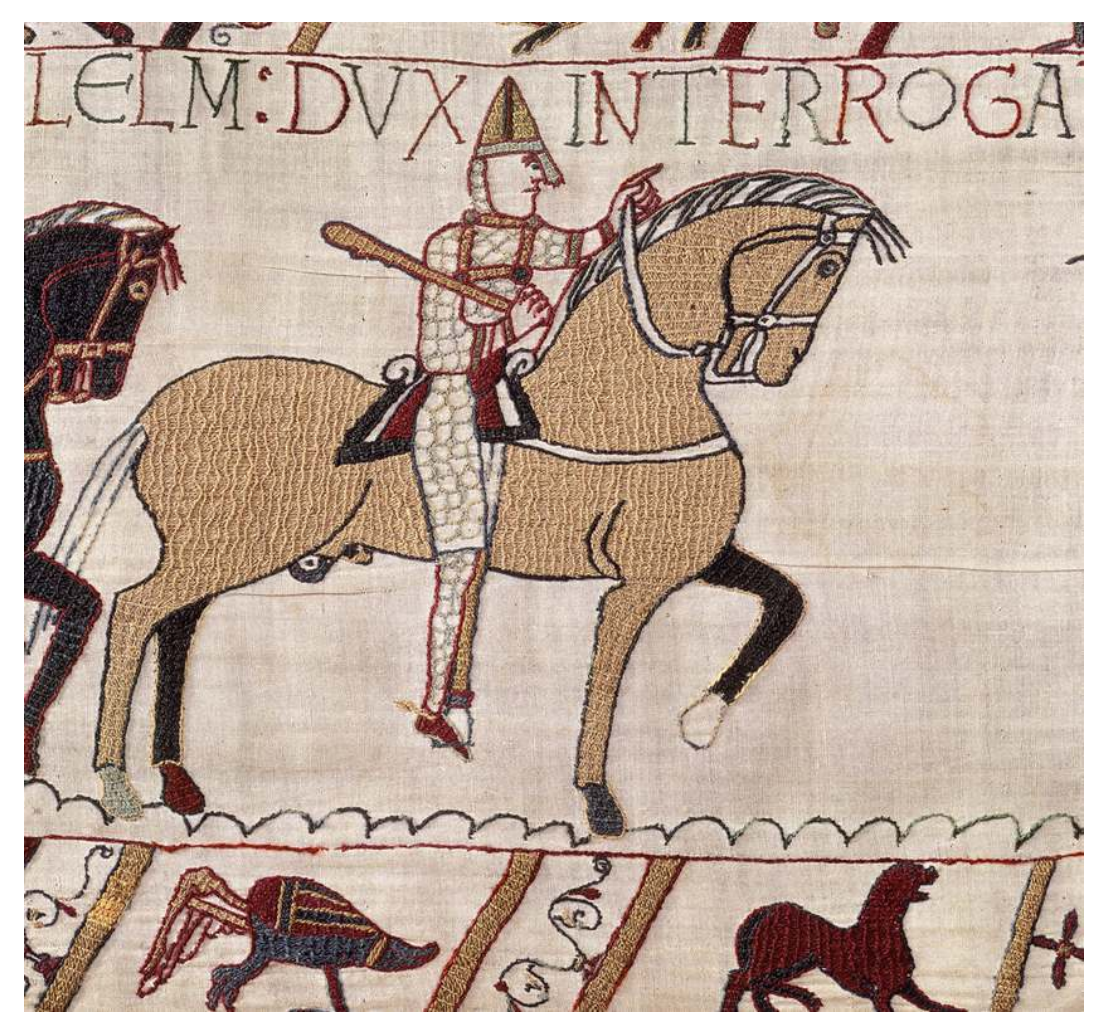

Scène 49 : Cheval au pas.

(C) Musées de la ville de Bayeux.

Le trot semble représenté par les deux avant-bras des antérieurs levés parallèlement (fig. 14). Quant au galop, dont l'analyse précise du mouvement n'a été possible qu'avec la découverte de la photographie, il est suggéré par les deux antérieurs (avant-bras et canons) lancés presque à l'horizontale tandis que les deux postérieurs sont tendus vers l'arrière. Le cheval flotte alors en l'air, car aucun de ses membres ne repose sur le sol, ce qui constitue d'ailleurs un des temps réel du galop, le temps de suspension (fig. 15). 
Figure 14

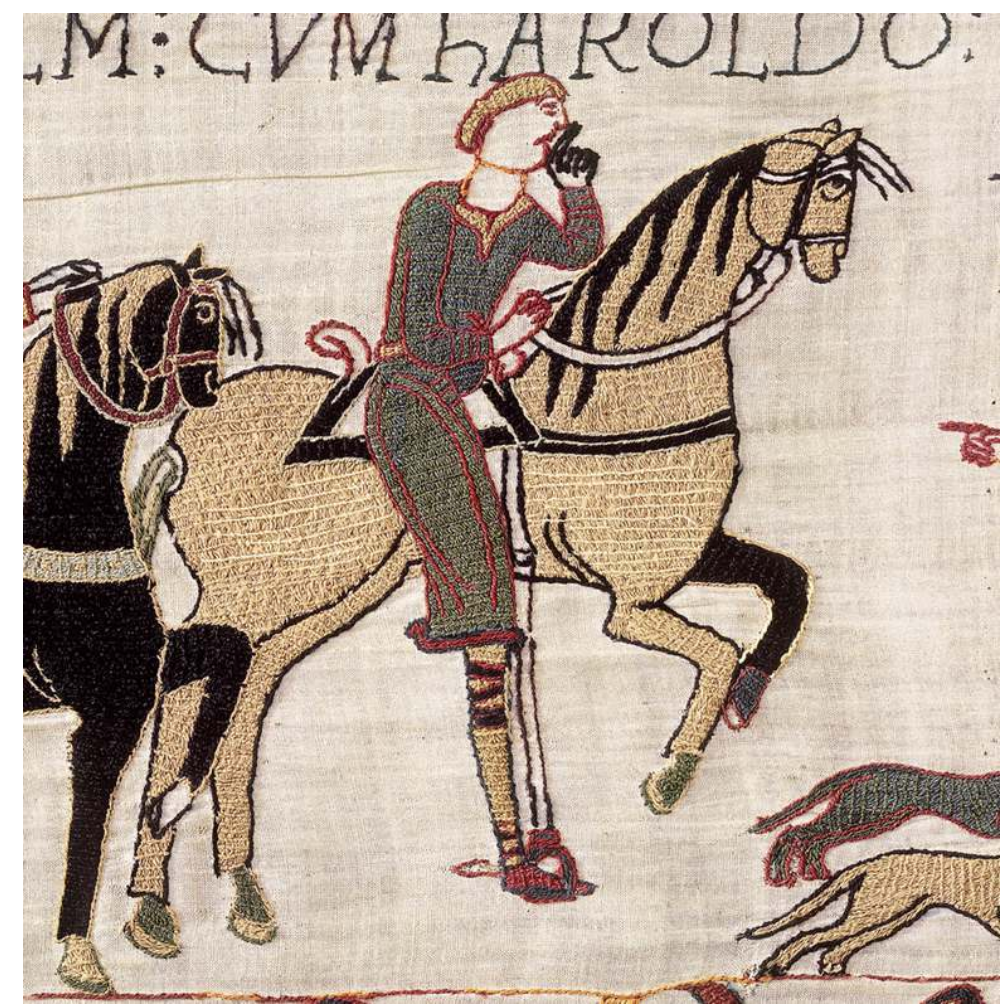

Scène 14 : Cheval au trot

(c) Musées de la ville de Bayeux.

Figure 15

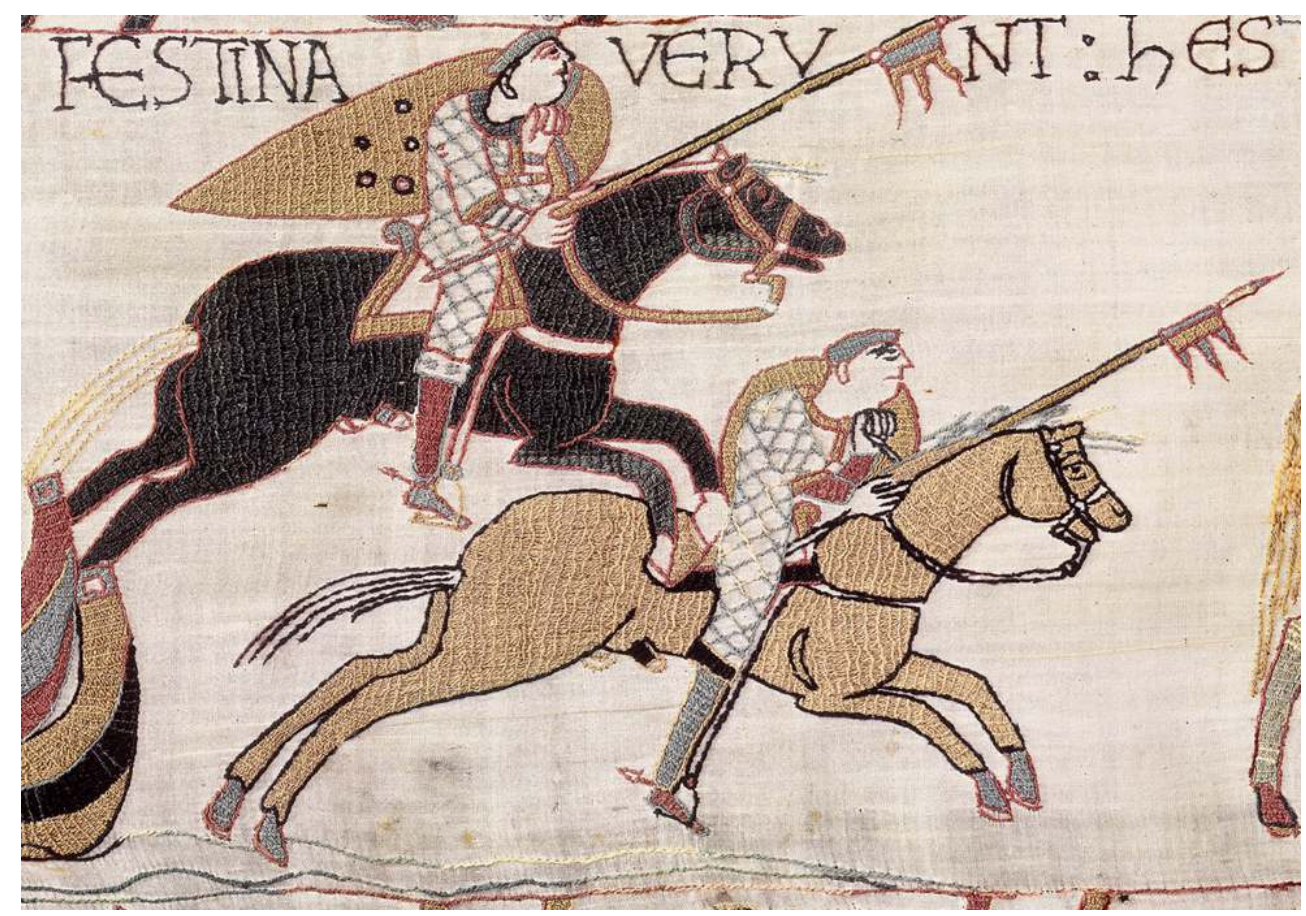

Scène 40 : Chevaux au galop.

(c) Musées de la ville de Bayeux. 
On a exceptionnellement représenté le cheval marchant à l'amble dans la scène 8 où le prétentieux Guy de Ponthieu fait prisonnier Harold (fig. 16) et dans la scène 50 où Harold sur sa monture apprend l'arrivée des Normands.

Figure 16

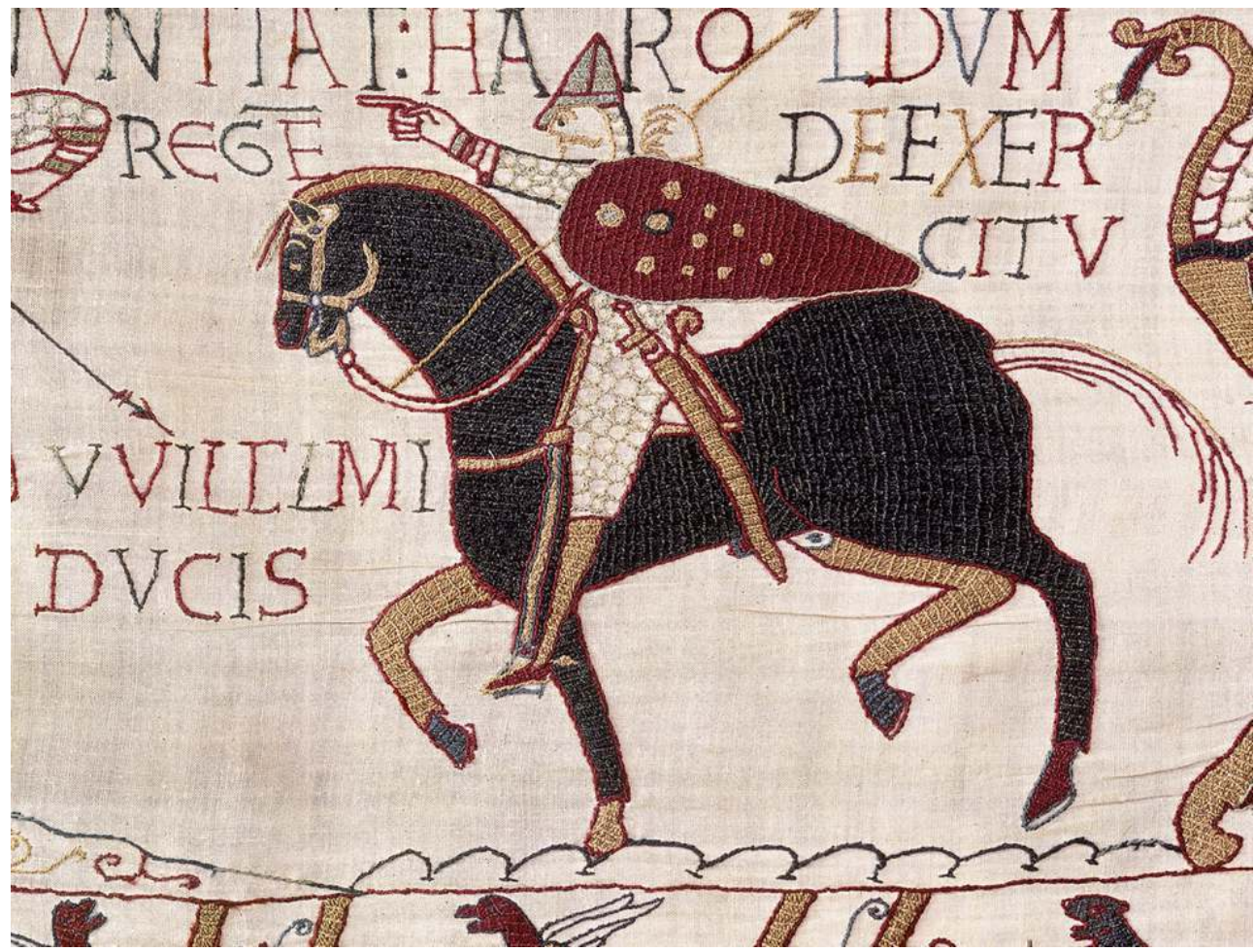

Scène 50 : Harold sur son cheval marchant à l'amble.

(c) Musées de la ville de Bayeux.

En dehors de ces allures habituelles, certains chevaux adoptent des postures anormales. L'une des plus belles scènes de la tapisserie de Bayeux évoque un moment dramatique de la bataille. Après la mort de Harold, les Anglais prirent la fuite à travers la forêt, poursuivis par la cavalerie normande. Mais certains fuyards reprirent courage et s'installèrent au sommet d'une éminence qui dominait des fosses profondes remplies d'eau. 


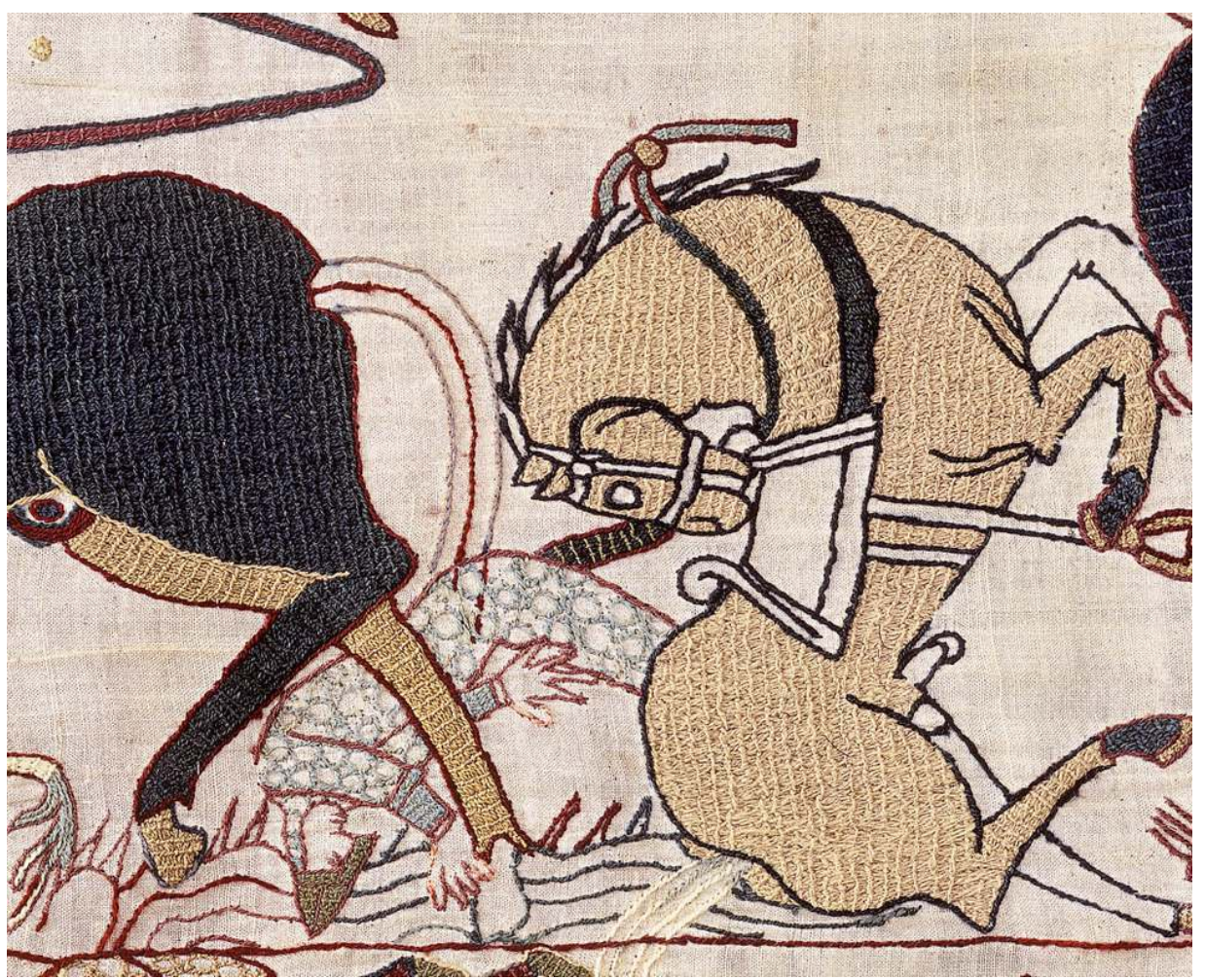

Scène 53 : Chute du cheval beige à la renverse.

(c) Musées de la ville de Bayeux.

Cet épisode final fut si violent que, selon Guillaume de Poitiers, le comte Eustache de Boulogne songea lui-même à fuir : «Dans ce combat tombèrent quelques-uns des plus fameux guerriers normands auxquels l'âpreté du lieu ne permit pas de donner la pleine mesure de leur vaillance ${ }^{8} »$. Sur la tapisserie de Bayeux, cet incident est placé avant la mort de Harold. Un cheval jaune/beige s'est cabré si violemment qu'il s'écroule, entraînant son cavalier dans sa chute dans l'eau de la fosse (fig. 17). Le cheval bleu tombe la tête en avant ; il a perdu la selle et les sangles ainsi que son cavalier : il est à la verticale et tout son corps demeure quelques secondes en équilibre instable avant de basculer d'un côté ou de l'autre (fig. 18). 


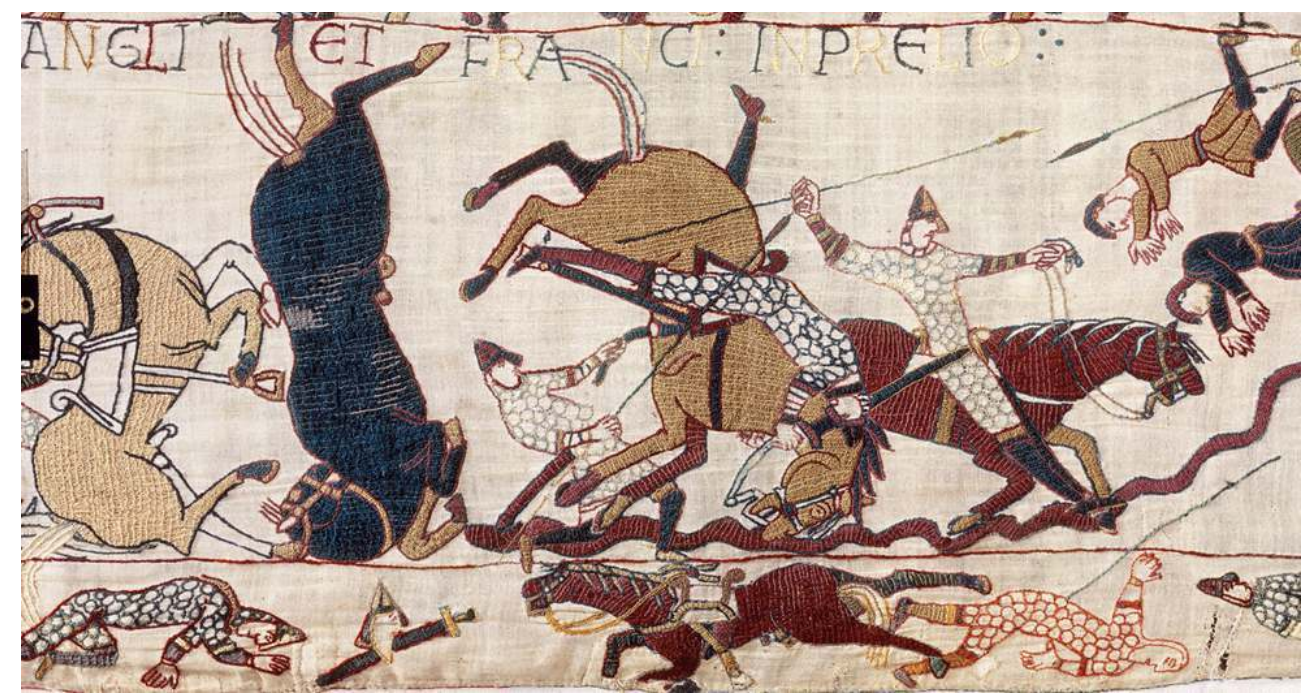

Scène 53 : Chute du cheval bleu noir en avant.

(c) Musées de la ville de Bayeux.

C'est cet instant privilégié que les dessinateurs ont choisi pour représenter ces deux chevaux magnifiques, à la manière des reporters de guerre à l'affût du cliché émotionnel. En examinant le cheval beige qui suit, on peut comprendre ce qui est arrivé au cheval bleu. Comme l'animal semble s'être empêtré les pieds dans un sol instable et irrégulier, un fantassin anglais profite de cet instant pour détacher la sous-ventrière, ce qui provoque inévitablement la chute du cavalier normand (fig. 19). Ces trois chevaux en déséquilibre évoquent la violence des combats non seulement pour les humains, mais également pour les animaux condamnés à partager la folie meurtrière de leurs maîtres. On ignore le nombre de chevaux qui furent blessés ou tués lors de ce samedi 14 octobre 1066 . 
Figure 19

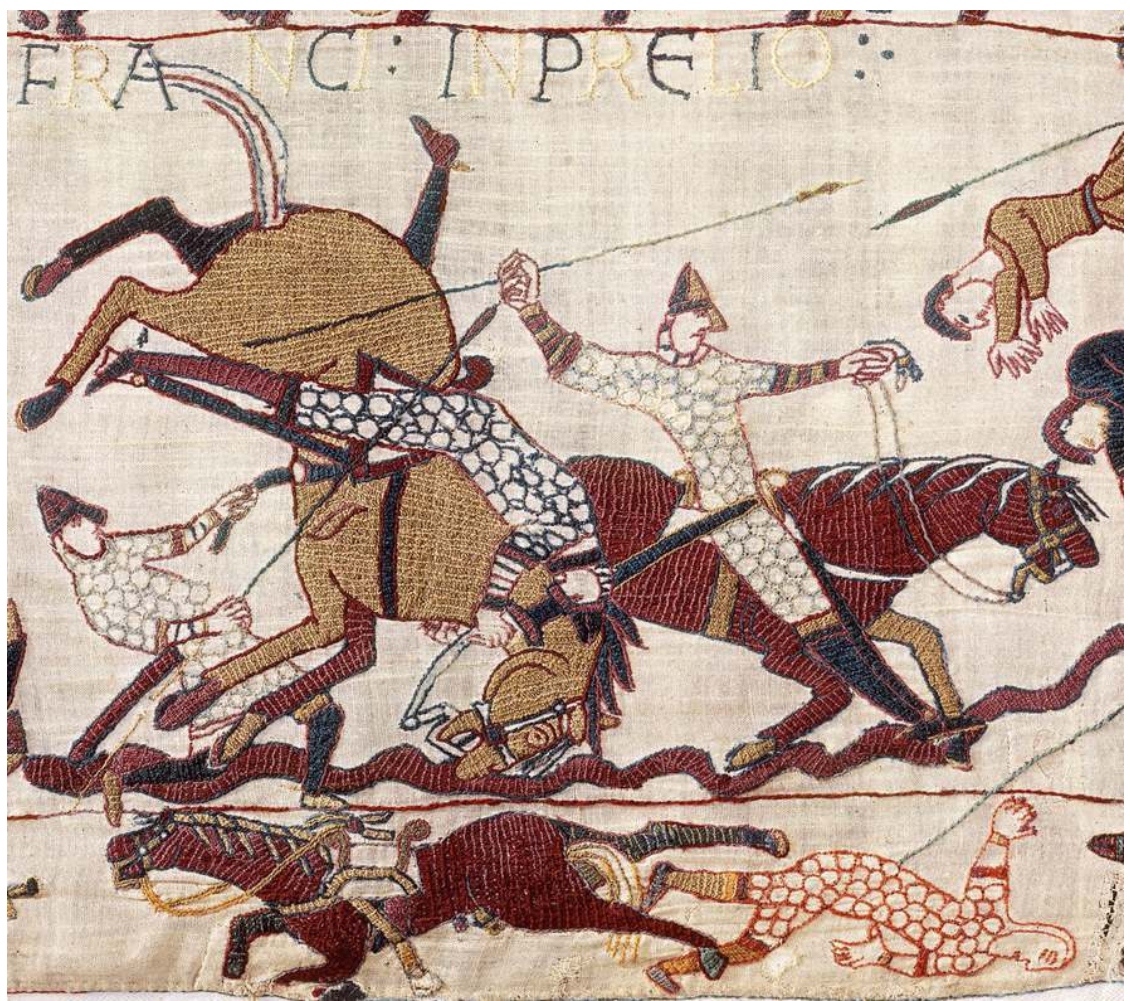

Scène 53 : Autre cheval beige qui trébuche, tandis qu'un Anglais détache la sangle. (c) Musées de la ville de Bayeux.

Lors de la traversée de la baie du Mont Saint-Michel, où Harold accomplit un exploit en sauvant des sables mouvants deux hommes, un Normand et un Anglais, un cheval s'enlise dans les grèves en faisant tomber son cavalier (fig. 20). 


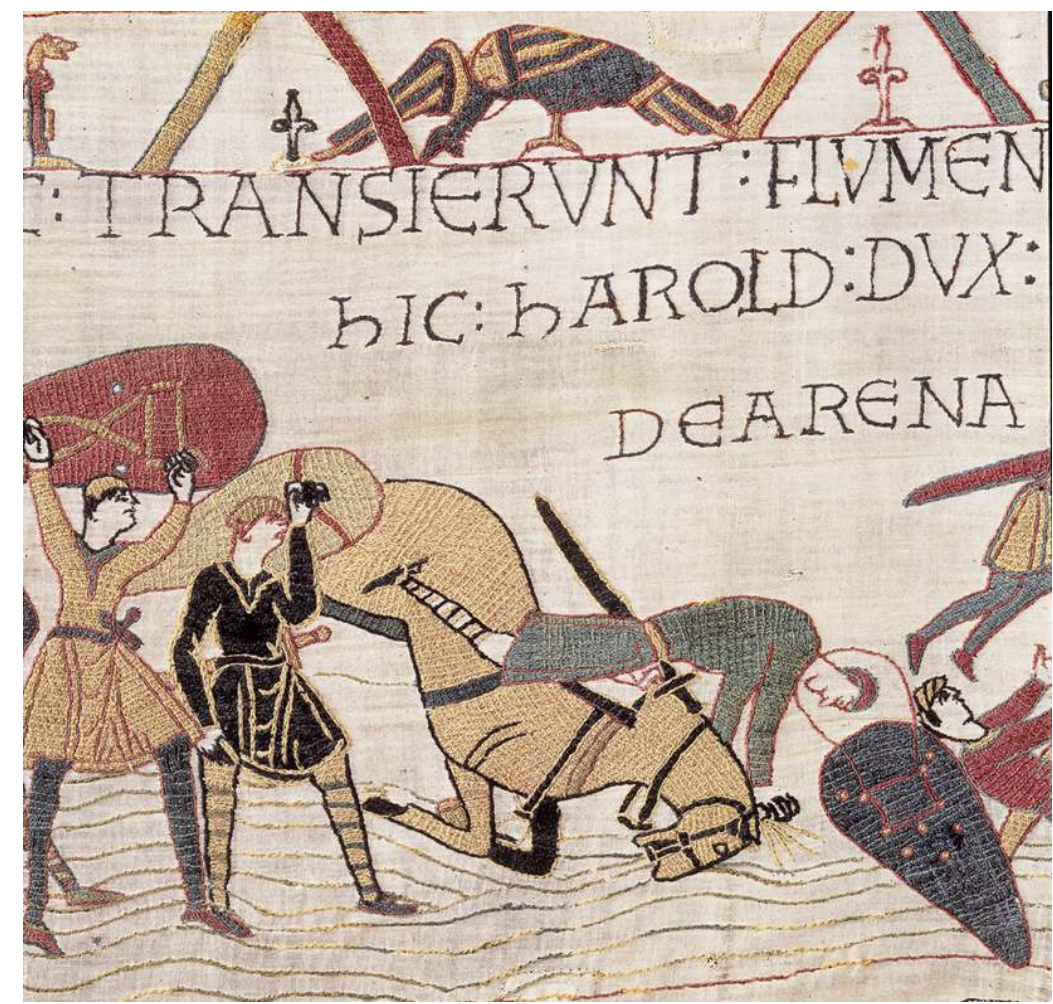

Scène 17 : Cheval qui tombe dans les sables mouvants de la baie du Mont Saint-Michel.

(c) Musées de la ville de Bayeux.

Le chevalier qui précède, voyant le danger, préfère sauter de sa monture, de curieuse façon, pour effectuer la traversée du Couesnon (fig. 21). À la scène 11, deux chevaux tenus par les rênes ne semblent pas apprécier leur immobilité : l'un piaffe d'impatience tandis que l'autre redresse la tête et se cabre (fig. 22). Le palefrenier est un petit homme barbu qui a suscité de nombreux commentaires: on se demande toujours si c'est un nain ou si le personnage est petit en raison de la perspective ? Par ailleurs, est-ce lui qui porte le nom de Turold ou le chevalier qui est juste à côté de lui? 


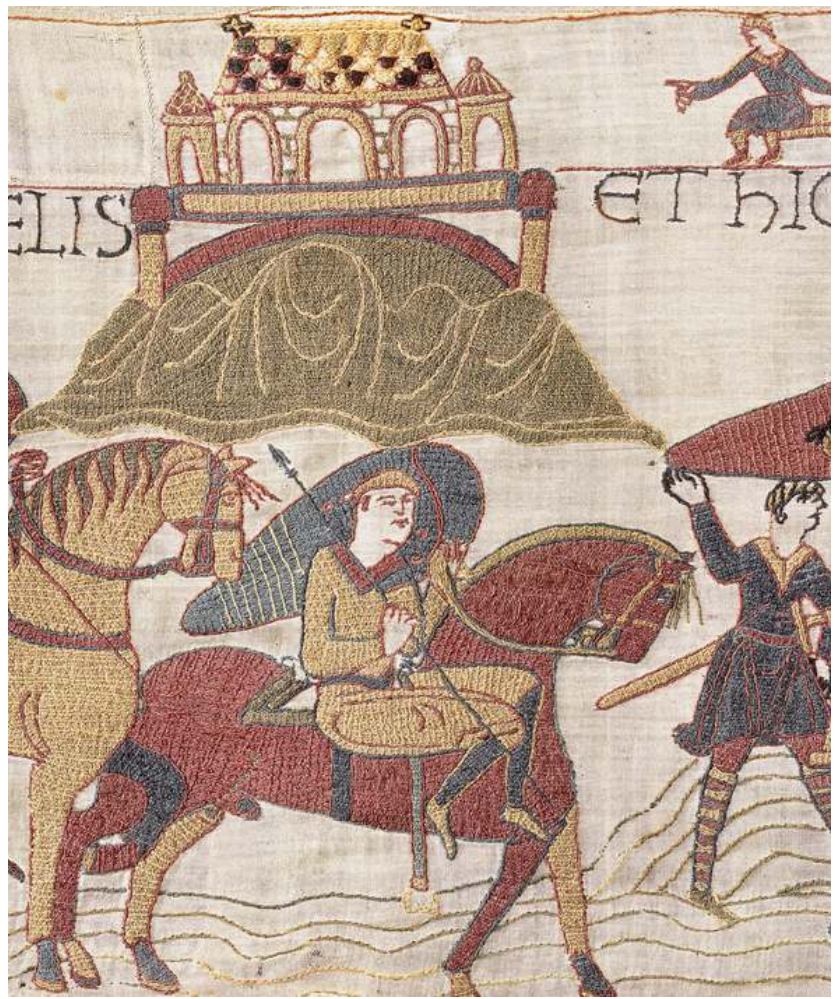

Scène 17 : Derrière le cheval qui tombe dans les sables mouvants de la baie du Mont Saint-Michel, un cavalier saute précipitamment de son cheval.

(c) Musées de la ville de Bayeux.

Figure 22

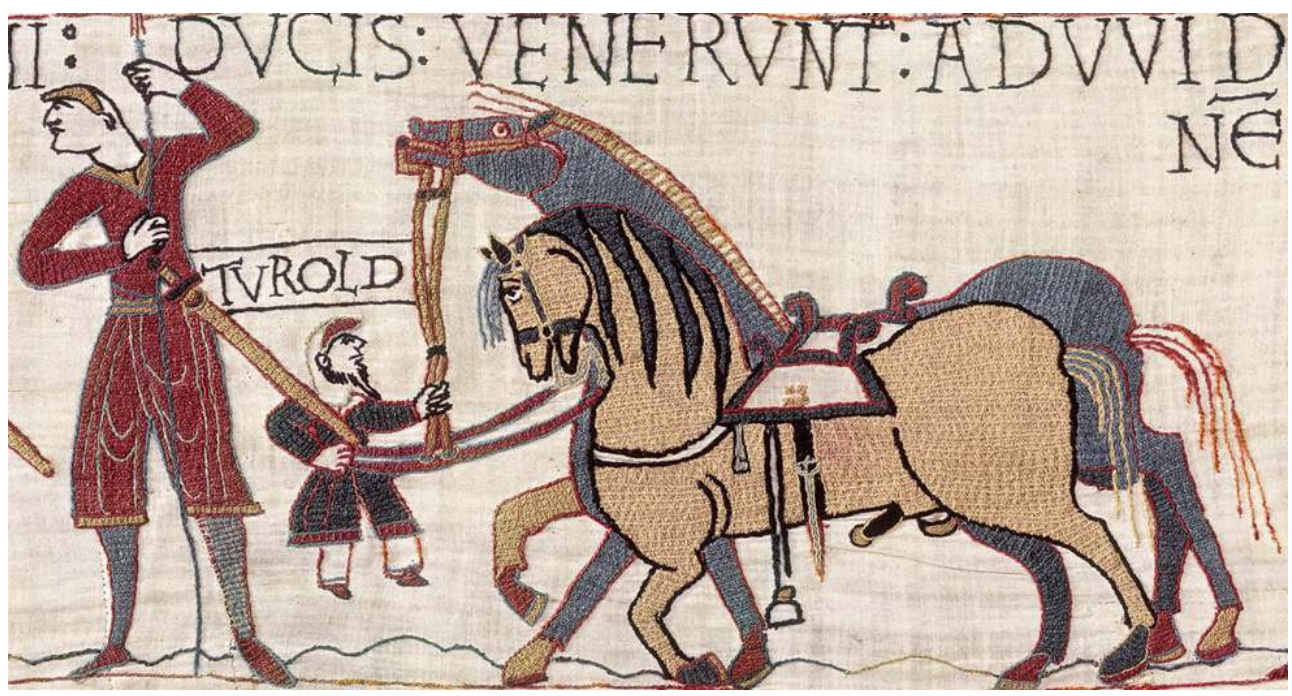

Scène 10 : Deux chevaux récalcitrants tenus par un petit palefrenier.

(c) Musées de la ville de Bayeux.

Les chevaux, tout comme les navires, ne défilent pas devant les yeux des spectateurs sur une seule ligne. Les dessinateurs ont cherché à donner de la profondeur aux différents tableaux en utilisant deux techniques. Tous les chevaux sont brodés avec des fils de laine 
de la même couleur, mais les jambes, du côté qui échappe au regard, sont d'une autre couleur. On a ainsi l'impression que l'animal prend de l'épaisseur et que la seconde couleur joue le rôle de l'ombre. Il y a un jeu de couleurs complémentaires entre celle du cheval et celle de l'intérieur des membres ainsi aperçus. Un relevé sommaire montre que toutes les combinaisons sont possibles : sur 21 chevaux beiges, 10 ont l'ombre des jambes en noir, 6 l'ont en vert et 5 en rouge. Sur 11 chevaux rouges, 7 ont une ombre de couleur beige, 4 l'ont en noir et 2 en vert. Exceptionnellement, le cheval peut être entièrement de la même couleur : tout entier en rouge, en vert, en beige ou en bleu noir.

L'autre procédé est celui de la superposition de plusieurs chevaux, de manière à ce que l'on aperçoive quand même soit la croupe soit la tête. Ce procédé crée une profondeur de champ qui donne l'impression d'un groupe compact de chevaliers sur plusieurs rangs (fig . 23). Les animaux se cachent partiellement, de sorte qu'il est aisé de dénombrer soit les croupes soit les têtes. Parfois le groupe est si compact que le compte en têtes de chevaliers ou en jambes des chevaux est inadéquat: les dessinateurs n'ont pas voulu ou pas pu faire figurer tous les membres des chevaux. Ainsi, à la scène 8, quatre cavaliers suivent de près Harold: on peut aisément les identifier aux croupes de leurs chevaux, mais on n'aperçoit que douze jambes au lieu de seize. En réalité le groupe est constitué de six chevaliers, mais deux chevaux sont absents car entièrement masqués par les chevaux du premier plan.

Figure 23

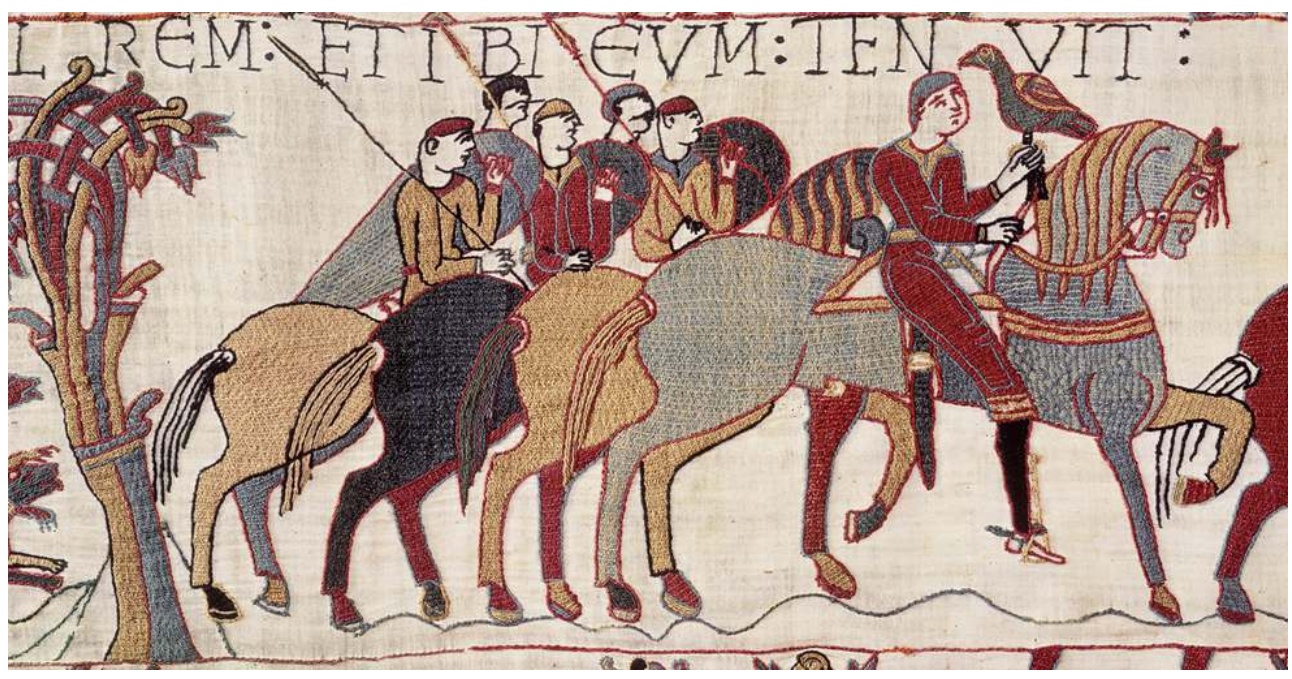

Scène 8 : Groupe de chevaliers conduisant Harold à Beaurain.

(c) Musées de la ville de Bayeux.

La scène 48 mérite un arrêt sur image (fig. 24). Les dessinateurs ont disposé la cavalerie normande sur onze plans : les chevaux se superposent en partie et donnent l'impression d'un groupe bien ordonné. Ce tableau des chevaliers normands se préparant au combat ne représente pas un temps unique, comme dans la bande dessinée ou sur un cliché photographique. Cette scène doit s'interpréter en distinguant plusieurs moments (fig. 25) . Le premier cavalier qui a sa lance posée sur son étrier est au repos, la lance dirigée négligemment vers l'arrière. Les chevaliers suivants tiennent leur lance à la verticale : ils ne sont plus « au repos ", mais se préparent à l'action. Les trois derniers du groupe avant le chevalier à la bannière inclinent leurs lances vers l'avant, indiquant par là que leur 
monture est en mouvement. Les trois derniers cavaliers, quelque peu espacés, sont lancés au galop pour prendre position derrière leur duc.

Figure 24

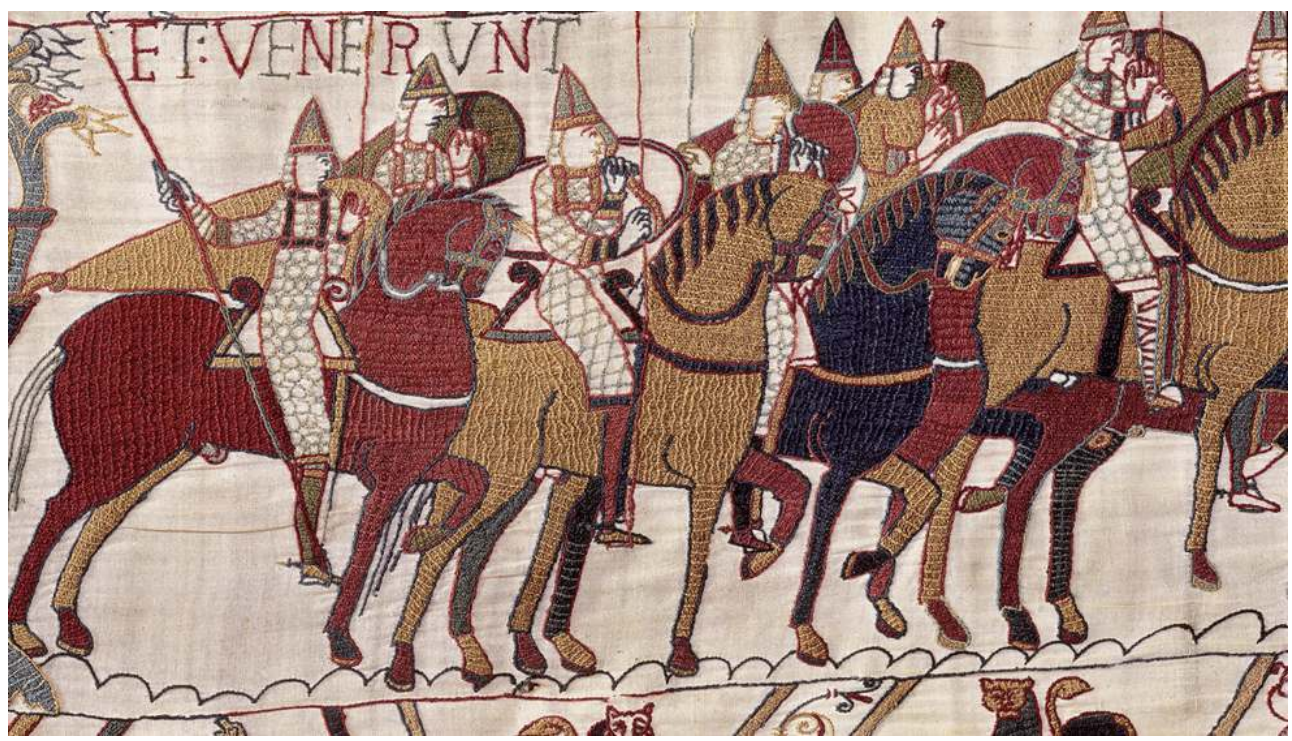

Scène 48 : La cavalerie normande se met en branle au début de la bataille de Hastings. (c) Musées de la ville de Bayeux.

Figure 25

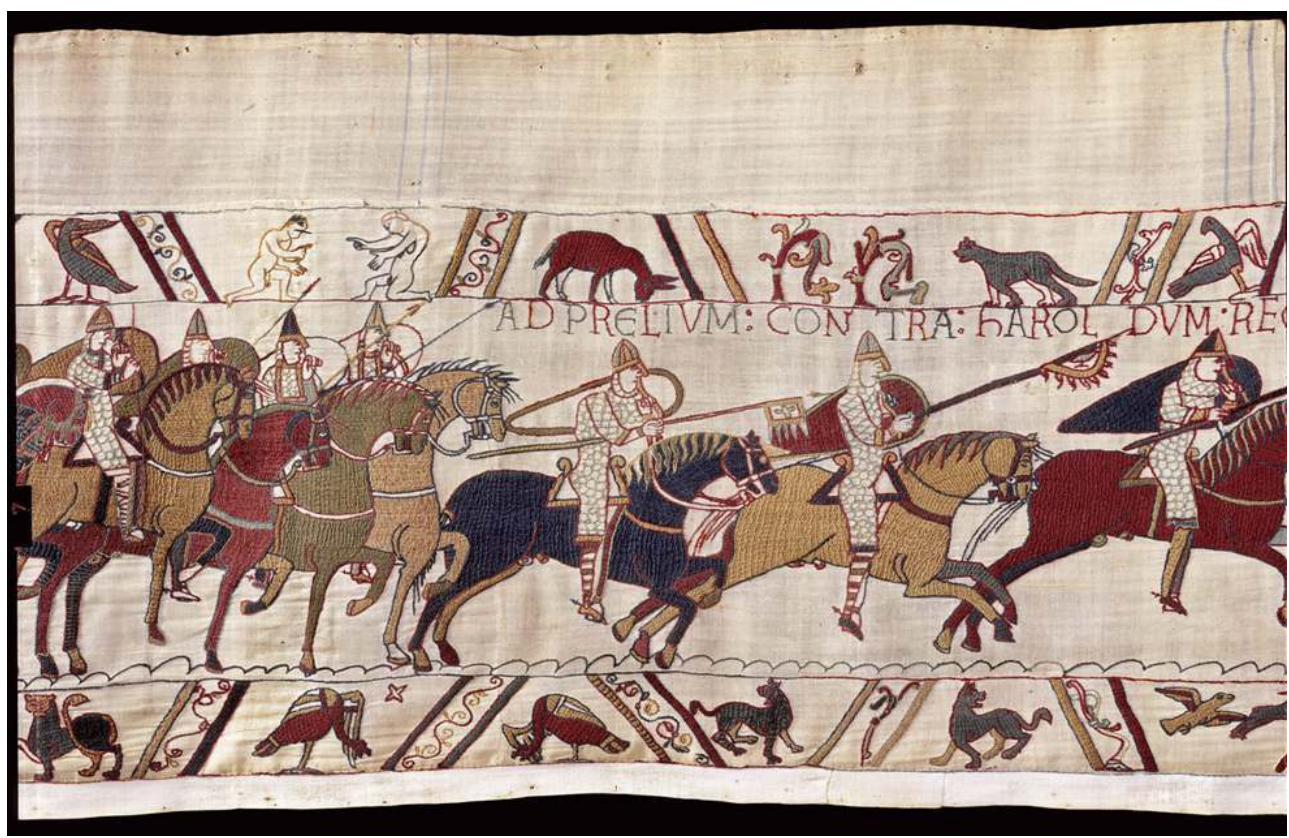

Scène 48 : La cavalerie normande se met en branle au début de la bataille de Hastings, suite de la même scène.

(c) Musées de la ville de Bayeux. 


\section{Conclusion}

\section{BIBLIOGRAPHIE}

Bibliographie de Pierre Bouet :

La Tapisserie de Bayeux : l'art de broder l'histoire. Actes du colloque international de Cerisy-la-Salle, 1999 (en collaboration avec B. Levy et F. Neveux). Presses universitaires de Caen, 2003.

Guillaume le Conquérant et les Normands au XI siècle. Condé-sur-Noireau : Éd. Corlet, 2003.

Hastings, 14 octobre 1066. Paris : Tallandier, 2010 (réédition 2014).

La Tapisserie de Bayeux. Révélations et Mystères d'une broderie du Moyen Âge (en collaboration avec François Neveux). Éd. Ouest-France, 2013.

\section{NOTES}

1. - Les images de cet article sont présentées avec l'aimable autorisation des musées de la ville de Bayeux.

2. - Voir BOUET, Pierre. «La tapisserie de Bayeux, une œuvre pro-anglaise?». Dans BOUET, Pierre, LÉVY, Brian et NEVEUX, François (dir.). La tapisserie de Bayeux. L'art de broder l'Histoire (Actes du colloque international de Cerisy-la-Salle, octobre 1999). Caen : Presses universitaires de Caen, 2004, p. 197-215.

3. - De POITIERS, Guillaume. Histoire de Guillaume le Conquérant, éd. Raymonde Foreville. Paris : Les Belles Lettres, 1952, I, 13, p. 26. 
4. - La famille Tesson possédait des haras dans le Bessin, le Cotentin et le Cinglais, les Marmion en possédaient près de Fontenay (au sud de Caen), les Bellême disposaient de nombreux haras dans l'Orne et particulièrement dans le Perche (le cheval du Merlerault était un animal apprécié, selon Orderic Vital). Les ducs de Normandie eux-mêmes n'étaient pas en reste : ils entretenaient des centres d'élevage dans la vallée de la basse Seine (aux Andelys, à Longboël, à Maulévrier, à Lillebonne, au Vaudreuil, etc.) et en basse Normandie (près de Caen, près de Falaise et dans la Manche) ; voir HOUEL, Ephrem. Le cheval normand au Moyen Âge. Caen : Le Blanc-Hardel, 1881.

5. - BOUET, Pierre. Hastings, 14 octobre 1066. Paris : Tallandier, 2011, p. 60-88.

6. - WACE. Roman de Rou, éd. Anthony J. HOLDEN. Paris : Picard, 1971, vers 7535-7542 : « Son boen cheval fist demander / Ne poeit l'en meillor trover / D'Espaigne li out enveié / uns reis par mult grant amistié / Gautier Giffart l'out amené / qui a saint Jame aveit esté ».

7. - De POITIERS, Guillaume, op. cit., II, 22, p. 198.

8. - Ibid., II, 24, p. 204.

\section{RÉSUMÉS}

Les dessinateurs de la tapisserie de Bayeux étaient de véritables amoureux des chevaux qui figurent en nombre sur cette broderie (près de 200). Ces animaux sont dessinés avec une extrême précision, qui nous permet de connaître les différentes pièces du harnachement et les techniques du combat à cheval, dont les Normands étaient les spécialistes. On doit également porter un regard esthétique sur la façon dont tous ces chevaux ont été représentés et mis en scène : les artistes de la tapisserie avaient leurs propres techniques pour représenter le mouvement et la perspective, notamment dans les scènes de bataille. La tapisserie est loin de répondre à toutes nos interrogations : les sources historiographiques doivent être mises à contribution pour que nous puissions mieux apprécier ce que fut, en ce milieu du XI ${ }^{\mathrm{e}}$ siècle, la société normande, où le cheval occupait une place de choix.

The horses in the Bayeux tapestry. The makers of the Bayeux tapestry were very keen on horses which feature throughout the embroidery, about 200 in all. They are depicted with great precision, giving us an insight into the different pieces used for harnessing the horses and into the techniques of mounted fighting, at which the Normans were expert. An aesthetic appreciation is also possible of the way the horses are depicted and staged. The artists of the tapestry had their own techniques for the representation of movement and perspective, particularly in the battle scenes. The tapestry does not answer all our questions however, and other sources are needed to understand Norman society towards the middle of the eleventh century, a society in which the horse occupied a special place.

\section{INDEX}

Mots-clés : cheval, mulet, hongre, harnachement, haras, Normandie, bataille de Hastings, chevalier, Guillaume le Conquérant, tapisserie de Bayeux

Keywords : horse, mule, gelding, harness, Normandy, battle of Hastings, knight, William the Conqyeror, Bayeux tapestry 


\section{AUTEUR}

\section{PIERRE BOUET}

Maître de conférences honoraire de l'Université de Caen Basse-Normandie, Directeur honoraire de l'office universitaire d'études normandes de l'université de Caen pfbouet@free.fr 